\title{
R-spondin 3 deletion favors Erk phosphorylation to enhance Wnt signaling and bone formation
}

\section{Kenichi Nagano}

Harvard School of Dental Medicine and Harvard Medical School

\section{Kei Yamana}

Harvard School of Dental Medicine and Harvard Medical School

Hiroaki Saito

Harvard School of Dental Medicine

\section{Riku Kiviranta}

University of Turku

\section{Ana Clara Pedroni}

Harvard School of Dental Medicine and Harvard Medical School

\section{Dhairya Raval}

Harvard School of Dental Medicine and Harvard Medical School

\section{Christof Niehrs}

German Cancer Research Centre (DKFZ)

Francesca Gori ( $\square$ francesca_gori@hsdm.harvard.edu )

Harvard School of Dental Medicine and Harvard Medical School

\section{Roland Baron}

Department of Medicine, Harvard Medical School https://orcid.org/0000-0001-5784-5934

\section{Article}

Keywords: R-spondin 3, skeletal homeostasis, Erk signaling, Wnt signaling

Posted Date: September 3rd, 2021

DOI: https://doi.org/10.21203/rs.3.rs-569623/v2

License: (c) (i) This work is licensed under a Creative Commons Attribution 4.0 International License.

Read Full License 


\section{Wnt signaling and bone formation}

3 Kenichi Nagano ${ }^{1}$, Kei Yamana ${ }^{1}$, Hiroaki Saito ${ }^{1}$, Riku Kiviranta ${ }^{1}$, Ana Clara Pedroni ${ }^{1}$, Dhairya Raval ${ }^{1}$, 4 Christof Niehrs ${ }^{2,3}$, Francesca Gori ${ }^{1^{*}}$ and Roland Baron ${ }^{4,5^{*}}$.

6 'Division of Bone and Mineral Research, Harvard School of Dental Medicine and Harvard Medical 7 School, ${ }^{2}$ Division of Molecular Embryology, DKFZ-ZMBH Alliance, Deutsches Krebsforschungszentrum 8 (DKFZ), 69120, Heidelberg, Germany, ${ }^{3}$ Institute of Molecular Biology (IMB), 55128, Mainz, Germany,

$9{ }^{4}$ Department of Medicine, Harvard Medical School, ${ }^{5}$ Endocrine Unit, Massachusetts General Hospital.

${ }^{*}$ Co-senior Authors

13 Key Words: R-spondin 3, skeletal homeostasis, Erk signaling, Wnt signaling.

Address correspondence to:

Francesca Gori

Division of Bone and Mineral Research

Department of Oral Medicine, Infection and Immunity

Harvard School of Dental Medicine

Boston, MA 02115

Tel: (617) 432-1940

Email: francesca gori@hsdm.harvard.edu

And

Roland Baron

Department of Medicine

Harvard Medical School

Boston, MA 02115

Tel: (203) 640-3536

Email: roland baron@hms.harvard.edu 


\section{Abstract}

Activation of Wnt signaling leads to high bone density. The R-spondin family of four secreted glycoproteins (Rspo1-4) amplifies Wnt signaling. In humans, RSPO3 variants are strongly associated with bone density, but how RSPO3 affects skeletal homeostasis is not fully understood. Here we show that in mice Rspo3 haplo-insufficiency or its targeted deletion in osteoprogenitors lead to an increase canonical Wnt signaling activation. Using mouse embryonic fibroblasts we show that Rspo3 deficiency leads to activation of Erk signaling, stabilizing $\beta$-catenin. Furthermore, Rspo3 haplo-insufficiency impairs Dkk1 efficacy in blocking canonical Wnt signaling and prevents the in vivo inhibition of bone formation and bone mass induced by osteoblast-targeted expression of $D k k 1$. We conclude that $R s p o 3$ haplo-insufficiency/deficiency boosts canonical Wnt signaling by activating Erk signaling and impairing Dkk1's inhibitory activity, which in turn lead to increased bone formation and bone mass.

\section{Introduction}

The Wnt signaling pathway controls cell fate decisions and tissue homeostasis during development and in the adult $(1,2)$. It is also involved in skeletal development and essential for the regulation of bone mass in the adult skeleton (3-5). Genetic or therapeutic activation of canonical Wnt signaling is associated with increased bone mass (3) and current therapeutic approaches aim at activating this pathway in patients with osteoporosis or osteogenesis imperfecta for instance (6).

Wnt signaling involves a large number of receptors and co-receptors, and of endogenous agonists and antagonists that, together, tightly regulate its activation (1-4). Due to this complexity, and even though Wnt signaling has been studied extensively in recent years in bone, several aspects of the mechanisms by which it regulates bone mass remain unclear. Similarly, the specific downstream events regulated by these various components of the Wnt signaling machinery and their interaction with other signaling cascades remain puzzling.

In this context, the fact that several studies have demonstrated that the four Roof plate-specific spondin, R-spondins (Rspo1 to 4), synergize with Wnt ligands to activate Wnt signaling $(4,7-13)$ raises 
59 the question of their potential role in skeletal development and homeostasis. This enhancement of Wnt 60 activity is attributed to the ability of Rspos to prevent the ubiquitination and degradation of the 61 Lrp5/6/Fzd receptor complex via Lgr4-6, closely related orphans of the leucin-rich repeat containing G 62 protein-coupled receptors, and the transmembrane E3 ubiquitin ligases ring finger 43 (Rnf43) and zinc and ring finger 3 (Znrf3), sensitizing cells to Wnt ligands $(7,14-18)$. Although the role of Lgr receptors 64 in the effects of Rspos is well established, recent reports have shown that Rspo2 and Rspo3 can also enhance Wnt signaling independently of Lgr receptors, possibly by acting as direct antagonist ligands to RNF43 and ZNRF3 $(11,19,20)$.

Of particular interest is the fact that, in contrast to the many studies that have reported that Rspos co-activate Wnt signaling, some studies in Zebrafish have indicated that Rspo3 can also function as a negative regulator of canonical Wnt signaling during dorsoventral and anteroposterior patterning (21, 22). Additionally, it has been shown that Rspos can potentiate non-canonical Wnt cascades, such as the Wnt/PCP signaling $(14,15)$ and can function as antagonists of BMPR1 in Xenopus $(23)$, two events that could have a negative impact on bone formation and bone mass. Thus, the mechanisms involved in the Rspos/Wnt signaling axis and their influence on skeletal homeostasis appear be more complex in vivo.

The four Rspos belong to a family of cysteine-rich secreted glycoproteins with high structural similarity and $60 \%$ sequence homology $(8,11)$. Although all Rspos are expressed in bone during development, they appear to have specific functions and their deletion in mice and human leads to different phenotypes $(10,13,24-31)$. Within the Rspo family, Rspo3 is of particular interest for bone because it is highly expressed in skeletal elements during mouse development $(32,33)$ and several human GWA studies have shown that RSPO3 SNPs are strongly associated with bone mineral density and risk of fracture (34-39). Not surprisingly, in vitro studies have shown that overexpression of, or treatment with, Rspos can enhance Wnt-ligand mediated osteoblast (OB) differentiation $(10,28,40)$. However, it has also been reported that Rspo3 may function as a negative regulator of osteoblast 
differentiation (41), raising questions about the true net influence of Rspos, and in particular Rspo3, on

85 skeletal homeostasis.

86 Thus, despite the consensus that Rspos co-activate Wnt signaling, Rspo3 may play a specific role

87 in skeletal biology, exerting a positive and/or a negative influence on bone. Little is known about its

91 increase bone mass.

\section{Methods}

\section{Biological Variables and Reproducibility}

To conduct the proposed studies, we insured strict application of scientific methods that supports robust and unbiased design, analysis, interpretation, and reporting of results, and sufficient information for all studies undertaken. In vivo analysis was performed in both gender. Given that our studies with Rspo3 mutant mice do not identify gender differences, and Dkk1-Tg mice did not show gender differences (42), studies including crossing with the two strains were performed in female mice. To avoid bias, data were collected in a blinded fashion, in that the observer was unaware of the experimental groups and more than one individual performed key studies. In vivo studies were performed with $n=4-10$ mice per genotype. We based this number on a priori calculations for power to detect differences in the primary outcomes skeletal phenotype by histomorphometric analysis. We found that based on three independent methods for measuring the skeletal phenotype 4-10 mice per group provide enough power $(80 \%$ to $90 \%)$ to find statistical significance at $p<0.05$. Ex vivo and in vitro studies involved at least three biological replicates per group/treatment.

\section{Animals}

Rspo3 mice were provided by Dr. Christof Niehrs (DKFZ-ZMBH Alliance, Germany) (27). The osteoblast specific Dkk1 transgenic (Dkk1-tg) mice were generously provided by Dr. Guo and Dr. Kronenberg (Massachusetts General Hospital, MA, USA) (42). Runx2Cre mice were provided by Dr. 
110 Tuckermann (Ulm University, Ulm, Germany) (43). All experiments were performed with age- and

111 gender-matched littermates. All animals are in the C57/BI6 background and were housed in the Harvard

112 Center for Comparative Medicine and all experimental procedures were approved by the Harvard University Institutional Animal Care and Use Committee.

\section{Skeletal phenotype}

For bone histomorphometric analysis, 612 or 18 wk-old mice were injected with $20 \mathrm{mg} / \mathrm{kg}$ of calcein and $40 \mathrm{mg} / \mathrm{kg}$ of demeclocycline (Sigma Aldrich, St. Louis, MO, USA) 6, 8 or 9 day, respectively and 2 day prior to the sacrifice. Bone histomorphometric analysis was performed within the proximal tibia under 200X magnification in a $0.9-\mathrm{mm}$ high and 1.3-mm-wide region where was $200 \mu \mathrm{m}$ away from the growth plate. The OsteoMeasure analyzing software (Osteometrics) was used to generate and calculate the data. Structural parameters (bone volume fraction (BV/TV), trabecular thickness (Tb.Th), trabecular number (Tb.N), and trabecular separation (Tb.Sp), Cortical Area, (Ct.A.), Total Area (T.Ar), Marrow Area, (Ma.Ar.), Cortical Bone Volume, (Ct.Bv/TV and) Cortical thickness, (Ct.Th.) were obtained by calculating the average of 2 different measurements from consecutive sections. The structural, dynamic, and cellular parameters were presented according to the standardized nomenclature (44).

\section{Flow Cytometry}

Bone marrow was analyzed by flow cytometry as previously described (45). Briefly, bone marrow cells were flushed from femurs and tibiae of 6-8-wk old wt or Rspo3 $3^{+/-}$mice and washed with Hank's Balanced Salt Solution (HBSS). Residual bone samples were further digested in $3 \mathrm{mg} / \mathrm{ml}$ type I collagenase (Worthington Biochemical Corp., Lakewood, NJ 08701, USA) for 1 hour at $37^{\circ} \mathrm{C}$ and released cells were mixed with flushed bone marrow cells. Cells were stained with LIVE/DEAD® Fixable Aqua Dead Cell Stain Kit (Thermo Fisher Scientific, Waltham, MA, USA), anti-lineage-AF700, anti-CD31-PE, anti-Sca-1-PB, anti-CD45-Cy7APC, and anti-CD51-biotin with streptavidin-APC antibodies (BioLegend, San Diego, CA , USA). Cells were analyzed on a FACS ARIAll upon exclusion of dead cells. 


\section{Bone Marrow Stromal Cells and calvarial osteoblasts}

Bone marrow cells were flushed from femurs and tibiae of $6-8$ wk-old wt or Rspo $3^{+/-}$mice and cultured in DMEM supplemented with $10 \%$ fetal bovine serum (FBS) and $1 \%$ penicillin $(100 \mathrm{U} / \mathrm{ml})$ and streptomycin $(100 \mu \mathrm{g} / \mathrm{ml})$ for 3 days (GIBCO, Thermo Fisher Scientific, Waltham, MA, USA). Adherent MSCs were counted, re-plated onto at a $5,000 / \mathrm{cm}^{2}$ density and RNA or protein isolated 3 days later. For colony forming unit assays, flushed bone marrow stromal cells were plated ( $3 \times 10^{6} / 6$ wells) for CFU(Fibroblast) $\mathrm{F}$ and CFU-OB assays. CFU-F was detected by staining with $0.2 \%$ crystal violet in $2 \%$ ethanol for 1 hour and CFU-OB was detected by alkaline phosphatase activity with Napthol AS-MX, n,n-dimethylformamide and Fast Blue RR salt (Sigma Aldrich, St. Louis, MO, USA). Calvarial OBs were isolated from 1-3-day old pups via serial enzymatic digestions and cultured as previously reported (46).

\section{Mouse Embryonic Fibroblasts (MEFs) Primary Culture}

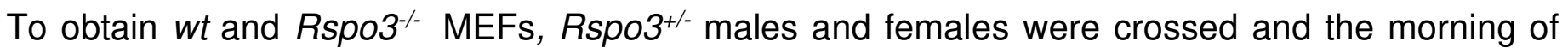
vaginal plug detection was defined as embryonic day (E) 0.5. At E9.5, whole embryos were isolated, washed in PBS, minced in $0.05 \%$ trypsin (GIBCO, Thermo Fisher Scientific, Waltham, MA, USA) followed by incubation at $37 \mathrm{C}$ for $10 \mathrm{~min}$. After incubation samples were pipetted to obtain single cell suspension and cells cultured in DMEM supplemented with 10\% FBS and 1\% penicillin/streptomycin. All the experiments were performed in passage 4 to 6 of wt or Rspo3 ${ }^{-/-M E F s . ~ C e l l s ~ w e r e ~ t r e a t e d ~ e i t h e r ~}$ 50 or $200 \mathrm{ng} / \mathrm{ml}$ of recombinant human Wnt3a, recombinant human Dkk1 (50-400 ng/ml), recombinant human Rspo3 (100 ng/ml) (all from R\&D system, Minneapolis, MN, USA) or U0126 $(10 \mu \mathrm{M}$ ) (Selleckchem, Houston TX, USA). For TOPflash luciferase reporter assay, cells were transiently cotransfected with $400 \mathrm{ng}$ TOPflash-luc reporter plasmid and $10 \mathrm{ng}$ control pCMV-Renilla-luciferase (Promega, Madison WI, USA) using Lipofectamine 2000 (Invitrogen, Thermo Fisher Scientific, Waltham, MA, USA) according to the manufacturers protocol. Cells were subjected to serum starvation in DMEM containing $1 \%$ FBS overnight. Cells were subsequently treated with recombinant human Wnt3a in the presence and absence of increasing concentration of Dkk1 for 24 hours followed by luciferase assay using the Dual-Glo Assay system (Promega, Madison WI, USA) according to the manufacturers 
protocol. Data were normalized by Renilla-firefly activity and presented as fold change compare to control group.

\section{Osteoclast Primary Culture and mix-matched co-cultures}

Murine bone marrow macrophages were isolated from bone marrow flushed tibiae and femurs of $w t$ and $R s p o 3^{+/-}$mice at 6 to 8 -wk-old as described previously (46). Briefly, cells were cultured in complete a-MEM with $30 \mathrm{ng} / \mathrm{ml}$ macrophage colony-stimulating factor M-CSF (R\&D system, Minneapolis, MN, USA) in suspension culture dish to which stromal cells and lymphoid cells cannot adhere, at $37^{\circ} \mathrm{C}$ for 2-3 days. For osteoclast generation, cells were cultured in $30 \mathrm{ng} / \mathrm{ml} \mathrm{M-CSF}$ and $10 \mathrm{ng} / \mathrm{ml}$ RANKL (R\&D systems, Minneapolis, MN, USA). For co-culture experiments, mouse calvarial osteoblasts were isolated from newborn $w t$ and $R s p o 3^{+-}$as previously reported $(46,47)$ and seeded in 96 -well plates (2.000 cells/well) in complete osteogenic a-MEM containing $100 \mathrm{nM}$ Vitamin D3 and $1 \mu \mathrm{M}$ prostaglandin E2 (Enzo Life Science, Farmingdale, NY, USA). After 3 days, 10,000 BMM from wt and Rspo3 $3^{+/}$mice at 6 to 8 -week-old mice were added per well and cocultured for 9 days in complete osteogenic $\alpha$-MEM. Tartrate-resistant acid phosphatase (TRAP) staining was performed to evaluate the number of osteoclasts according to the manufacture's protocol (Sigma-Aldrich, St. Louis, MO, USA).

\section{Western Blot Analysis}

Five $\mu \mathrm{g}$ of total protein were resolved by SDS-PAGE under reducing conditions. Immunodetection was performed with antibodies specific to: Active $\beta$-catenin, phosphorylated (p) Lrp6, p-Erk, total Erk, Tcf-1, Lrp6 and Tubulin (CST8814, CST2568, CST9101, CST9102, CST2203, CST3395, CST2125, Cell Signaling, Beverly, MA, USA) GAPDH and Actin (SC32233 and SC1616, Santa Cruz, Santa Cruz, CA, USA). Immunoreactivities were assessed using ECL plus kit following the manufacture's protocol (Perkin Elmer, Waltham, MA, USA). Quantification was performed using Image J. Protein levels were normalized to the levels of housekeeping protein or total protein in within the same sample.

\section{Quantitative-Real Time PCR}


Total RNA was isolated from cells using the RNeasy Mini Kit (Qiagen Germantown, MD, USA) according to the manufacturer's protocols. Total RNA from cortical bone of $w t$ and $R s p o 3^{+/-}$mice was extracted using Trizol reagent (Invitrogen) followed by RNeasy Mini Kit (Qiagen) according to the manufacturer's protocols. cDNA was synthesized using iScript cDNA synthesis kit (BIO-RAD. Hercules, CA, USA) and quantitative real time PCR performed. mRNA levels encoding each gene of interest were normalized for $\beta 2 \mathrm{M}$ or actin mRNA in the same sample and the relative expression of the genes of interest was determined using the formula of Livak and Schmittgen (48). Data are presented as fold change relative to wt cells or animals.

\section{Statistical Analysis}

Data are expressed as the mean \pm SEM or \pm SD. All experiments include at least three biological replicates and were done in duplicate or triplicate . Values represent the number of biological replicates. Statistical analysis was conducted using unpaired two-tail Student's t-test, or two-way ANOVA followed by post-hoc test for multiple comparisons. GraphPad PRISM 9 was also used for statistical analysis. A two-sided $p$-value of $<0.05$ was considered as the threshold for statistical significance.

\section{Results}

\section{Rspo3 haplo-insufficiency increases bone formation and trabecular bone mass.}

Rspo3 is expressed in bones during mouse skeletal development (32). We assessed Rspo3 mRNA levels in primary calvarial osteoblasts ( $\mathrm{COBs}$ ) and found that it is expressed in these cells and that its expression increases significantly during OB differentiation (Fig. S1a). To determine the physiological role of Rspo3 in skeletal homeostasis, we first used mice in which Rspo3 has been germline-deleted (27). As global deletion of Rspo3 leads to lethality by E9.5 $(24,27)$, before skeletal development, we analyzed mice lacking only one Rspo3 allele. These mice are born at the expected Mendelian ratio and their axial and appendicular skeleton develop normally (Fig. S1b). Rspo3 ${ }^{+/}$mice continue to be healthy and do not develop any particular pathology as they age (up to one year) (data not shown). However, contrary to expectations, two-way ANOVA analysis of the skeletal phenotype at 6,12 and 18-week (wk) of age (Fig.1a-b, Table 1, Table S1 and Fig. S1c), revealed highly significant $(p<0.001)$ anabolic effects 
213 of Rspo3 haplo-insufficiency on structural, cellular and dynamic parameters in both female and male

214 mice. The skeletal phenotype of $R s p o 3^{+/-}$male and female mice is overall characterized by an increase

215 in trabecular bone mass with high bone formation, mineral apposition rate and OB number and surface

216 whereas bone resorption parameters are not affected as indicated by OC number and surface as well

217 as eroded surface (ES/BS) (Fig.1a-b, Table 1,Table S1 and Fig. S1c).

218 
a
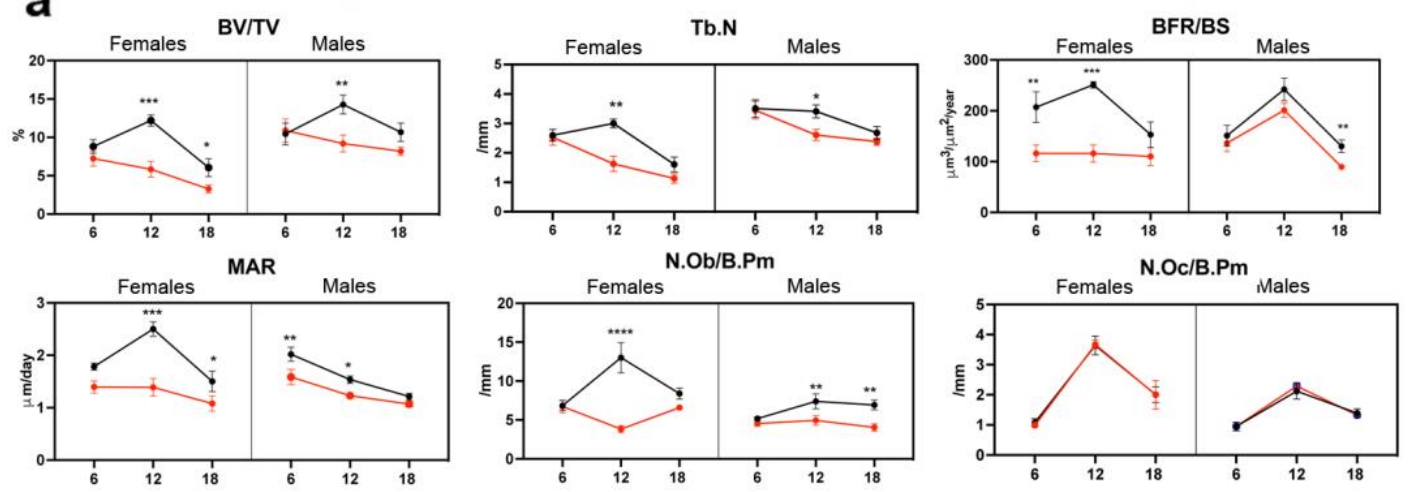

b
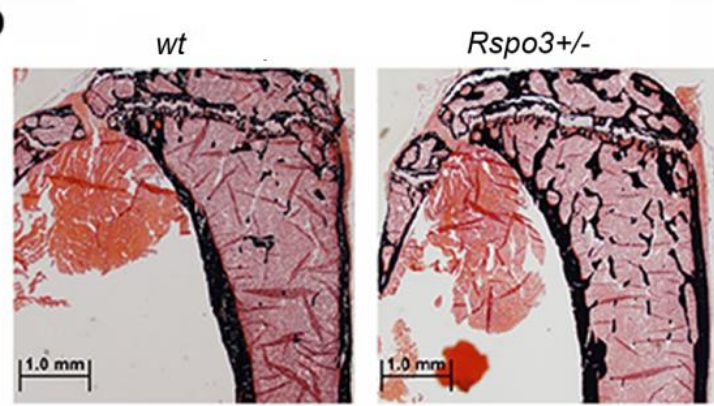

d

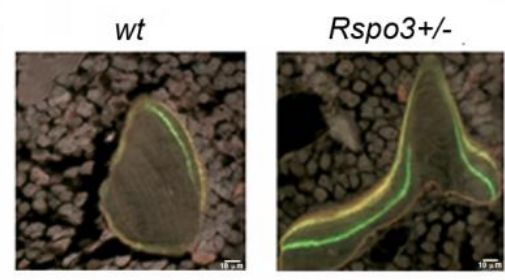

C
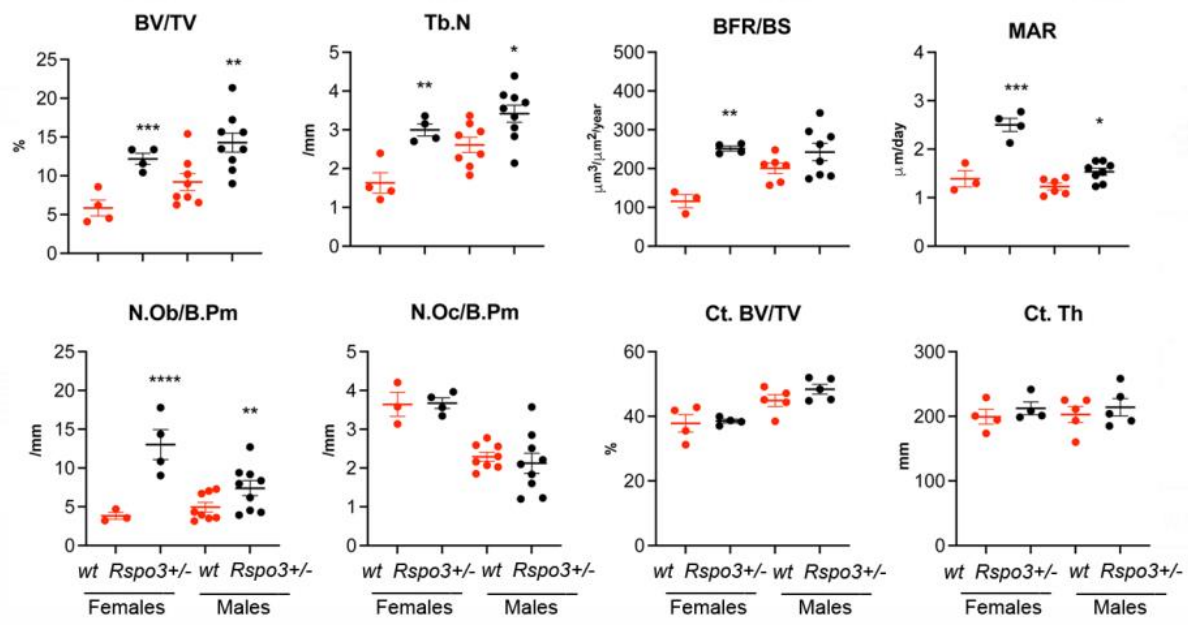

Figure 1. Skeletal phenotype of mice with Rspo3 haplo-insufficiency. a) Histomorphometric analysis in 6-, 12- and 18-wk males and females $(n=4-9)$. Data are the mean \pm SEM. Two Way ANOVA followed by Fisher's LSD test. ${ }^{*} p<0.05,{ }^{* *} p<0.005,{ }^{* * * *} p<0.0001$. b) Representative images of Von Kossa staining in 12 wk-old wt and Rspo3 $3^{+-}$male tibiae. c) Histomorphometric analysis of 12 wk-old wt and $R$ Rpo3 $^{+/-}$female and male tibiae $(n=4-9)$. Data show all samples and the mean \pm SEM. ${ }^{*}=p<0.05$, ${ }^{* *} \mathrm{p}<0.005$ by unpaired Student T-test. Red circles $=w t$, Black circles $=R s p o 3^{+/}$. d) Representative images of double labelling in trabecular bone in $12 \mathrm{wk}$-old $w t$ and $R s p o 3^{+/-}$male tibiae. 
As expected, the two-way ANOVA also demonstrated an effect of age, affecting primarily the structural parameters (Fig. 1a, Table 1 and Table S1). At 12 wk of age Rspo3 haplo-insufficiency led to a significant increase in trabecular bone mass (BV/TV), trabecular thickness (Tb.Th.) and trabecular number (Tb.N) (Fig. 1b and 1d, Table 1 and Table S1). In both genders trabecular bone resorption

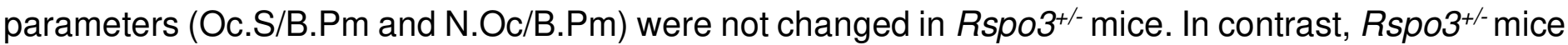
exhibited an increase in trabecular bone formation parameters (BFR/BS) (Fig. 1b-c, Table 1 and Table S1). This increase in BFR was associated with an increase in mineral apposition rate (MAR), indicating a marked increase in the activity of individual OBs in $R s p 3^{+/-}$mice, in addition to the increase in their numbers (N.Ob/B.pm, Fig. 1c, Table 1 and Table S1). Consistent with these results, the osteoid surface (OS/BS) and the OB surface (Ob.S/B.Pm) were also significantly increased in both genders (Table 1 and Table S1). Despite these marked effects on trabecular bone, cortical bone parameters were not significantly changed in $R s p o 3^{+/-}$female and male mice at $6-12$ or 18 wk of age (Fig. $1 \mathrm{~d}$, Table S2 and S3), indicating that Rspo3 haplo-insufficiency affects preferentially the trabecular bone compartment.

Thus, in contrast with the expectation that decreasing the expression of a Wnt signaling potentiator might lead to a decrease in bone mass, our data clearly indicates that Rspo3 haplo-insufficiency induces an increase in trabecular bone mass due to a significant increase in bone formation, with no changes in bone resorption. In agreement with our in vivo observations, we found that, although Rspo3 is expressed in bone marrow macrophage (BMM)-derived osteoclasts (OCs) (Fig. S2a), there was no significant differences in the formation of $\mathrm{TRAP}^{+}$multinucleated cells and in the expression of OC marker genes (Ctsk, Trap, Nfatc1) between BMM cultures from wt and Rspo3+/- mice in response to M-CSF and RANKL (Fig. S2b and 2Sc). In addition, mix-and-matched co-cultures of cOBs and BMMs from wt or Rspo3 ${ }^{+/-}$mice confirmed that Rspo3 haplo-insufficiency does not affect osteoclastogenesis, whether directly or indirectly (Fig. S2d). 
271 Table 1. Histomorphometric analysis of $R s p o 3^{+/-}$and wt females.

\begin{tabular}{|c|c|c|c|c|c|c|c|c|c|}
\hline \multirow[b]{2}{*}{ Parameters } & \multicolumn{2}{|l|}{$6 \mathrm{wk}$} & \multicolumn{2}{|l|}{12 wk } & \multicolumn{2}{|l|}{18 wk } & \multicolumn{3}{|c|}{ Two Way ANOVA } \\
\hline & $\begin{array}{l}w t \\
(n=6)\end{array}$ & $\begin{array}{l}\text { Rspo3 }^{+/-} \\
(\mathrm{n}=7)\end{array}$ & $\begin{array}{l}w t \\
(\mathrm{n}=4)\end{array}$ & $\begin{array}{l}\text { Rspo3 } 3^{+/-} \\
(\mathrm{n}=4)\end{array}$ & $\begin{array}{l}\text { wt } \\
(\mathrm{n}=8)\end{array}$ & $\begin{array}{l}\text { Rspo3 }^{+/-} \\
(\mathrm{n}=6)\end{array}$ & Genotype & Age & Interaction \\
\hline BV/TV (\%) & $7.24 \pm 0.98$ & $8.8 \pm 0.88$ & $5.84 \pm 1.01$ & $12.2 \pm 0.72^{\star \star \star}$ & $3.28 \pm 0.51$ & $6.06 \pm 1.1^{*}$ & $<0.0001$ & $<0.0001$ & NS \\
\hline Tb.Th $(\mu \mathrm{m})$ & $28.3 \pm 0.91$ & $33.6 \pm 1.5^{\star}$ & $35.8 \pm 2.54$ & $40.7 \pm 1.31$ & $28.2 \pm 1.55$ & $36.8 \pm 2.7^{* *}$ & 0.0003 & 0.0032 & NS \\
\hline Tb.N (/mm) & $2.53 \pm 0.27$ & $2.6 \pm 0.20$ & $1.63 \pm 0.26$ & $3.00 \pm 0.15^{\star \star}$ & $1.13 \pm 0.16$ & $1.61 \pm 0.25$ & 0.0025 & $<0.0001$ & 0.0429 \\
\hline Tb.Sp $(\mu \mathrm{m})$ & $397 \pm 52.6$ & $368 \pm 26.4$ & $618 \pm 86.8$ & $297 \pm 17.1^{*}$ & $1050 \pm 192$ & $690 \pm 133$ & 0.0378 & 0.0008 & NS \\
\hline $\operatorname{MAR}(\mu \mathrm{m} /$ day $)$ & $1.4 \pm 0.11$ & $1.8 \pm 0.06$ & $1.39 \pm 0.17$ & $2.5 \pm 0.14^{\star \star *}$ & $1.08 \pm 0.15$ & $1.5 \pm 0.20^{*}$ & $<0.0001$ & 0.0016 & NS \\
\hline MS/BS (\%) & $22.2 \pm 2.06$ & $31.4 \pm 4.05^{*}$ & $23.0 \pm 3.25$ & $27.8 \pm 1.63$ & $26.8 \pm 1.90$ & $27.3 \pm 1.55$ & 0.0394 & NS & NS \\
\hline $\begin{array}{l}\text { BFR/BS } \\
\left(\mu \mathrm{m}^{3} / \mu \mathrm{m}^{2} / \text { year }\right)\end{array}$ & $116.2 \pm 16.6$ & $207 \pm 30.4^{* *}$ & $116 \pm 16.9$ & $251 \pm 6.43^{* *}$ & $110 \pm 17.6$ & $153 \pm 25.1$ & $<0.0001$ & NS & NS \\
\hline $\begin{array}{l}\text { N.Ob/B.Pm } \\
(/ \mathrm{mm})\end{array}$ & $6.72 \pm 0.79$ & $6.85 \pm 0.64$ & $3.83 \pm 0.45$ & $13 \pm 1.94^{\star \star \star \star}$ & $6.60 \pm 0.39$ & $8.4 \pm 0.69$ & $<0.0001$ & NS & 0.0001 \\
\hline Ob.S/B.Pm (\%) & $10.3 \pm 1.20$ & $10.5 \pm 1.44$ & $4.89 \pm 0.38$ & $16.3 \pm 2.2^{* \star * *}$ & $9.66 \pm 0.52$ & $12.3 \pm 0.53$ & $<0.0001$ & NS & 0.0007 \\
\hline OS/BS (\%) & $4.68 \pm 0.78$ & $5.51 \pm 1.23$ & $2.51 \pm 0.30$ & $9.17 \pm 0.77^{\star \star \star}$ & $4.84 \pm 0.66$ & $8.3 \pm 0.74^{\star *}$ & $<0.0001$ & NS & 0.0263 \\
\hline O.Th $(\mu \mathrm{m})$ & $3.89 \pm 0.30$ & $4.64 \pm 0.37$ & $2.76 \pm 0.13$ & $4.36 \pm 0.09^{*}$ & $2.78 \pm 0.37$ & $4.24 \pm 0.3^{\star *}$ & 0.0003 & NS & NS \\
\hline $\begin{array}{l}\text { N.Oc/B.Pm } \\
(/ \mathrm{mm})\end{array}$ & $1.08 \pm 0.13$ & $0.99 \pm 0.11$ & $3.64 \pm 0.31$ & $3.67 \pm 0.14$ & $2.01 \pm 0.26$ & $2 \pm 0.48$ & NS & $<0.0001$ & NS \\
\hline Oc.S/B.Pm (\%) & $2.98 \pm 0.40$ & $3.07 \pm 0.37$ & $7.89 \pm 0.42$ & $8.77 \pm 0.55$ & $5.85 \pm 0.86$ & $5.7 \pm 1.17$ & NS & $<0.0001$ & NS \\
\hline ES/BS (\%) & $4.41 \pm 1.06$ & $4.05 \pm 0.42$ & $1.67 \pm 0.48$ & $2.96 \pm 0.43$ & $6.85 \pm 0.82$ & $6.74 \pm 1.28$ & NS & $<0.0001$ & NS \\
\hline
\end{tabular}

Data are expressed as Mean \pm SEM. Two Way ANOVA followed by Fisher's LSD post-hoc test. ${ }^{*}=p<0.05,{ }^{* *}=p<0.005,{ }^{* * *}=p<0.001,{ }^{* * * *}=p<0.0001$ compared to age-matched $w t$ females. 
Rspo3 haplo-insufficiency leads to an increase in bone marrow precursor cells and in their osteoblast potential.

Given that the OB number was significantly increased in mutant mice (Fig. 1, Table 1 and Table S1) we hypothesized an increase in the population of precursor cells. Bone marrow flow cytometry showed that while the total number of bone stromal cells (Lin-CD45-) was not significantly affected by Rspo3 haplo-insufficiency $\left(4047 \pm 1245\right.$ in wt compared to $5867+2382$ in $R s p o 3^{+/}$, mean \pm SEM $\left.n=10\right)$, the mesenchymal stromal cells (MSC) population (defined here as Lin-CD45-CD31-CD51+Sca-1+') was significantly increased in $R s p o 3^{+/-}$mice compared with wt littermates ( $\left.\mathrm{p}=0.015\right)$ (Fig. 2a and 2b) (45). Consistent with these findings and with the observed increase in $\mathrm{OB}$ number and bone formation, Rspo3 haplo-insufficiency significantly increased CFU-F $(p=0.04)$ and CFU-OB $(p=0.034)$ formation (Fig. 2c). These data show that the changes induced by Rspo3 haplo-insufficiency affect the bone marrow MSC lineage and induce an increase in the pool of progenitor cells with an osteoblast potential. 


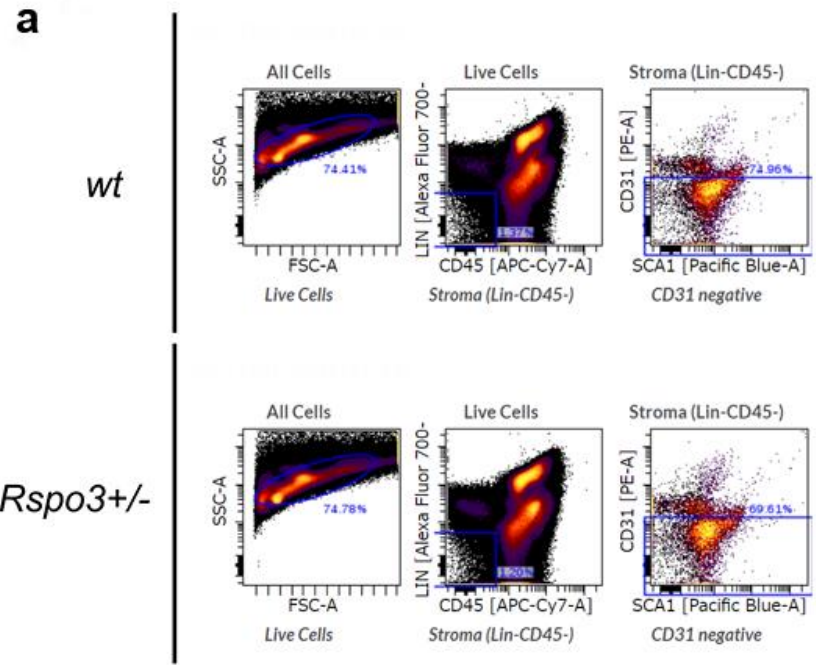

b

299

300

301

302

303

304

305

C
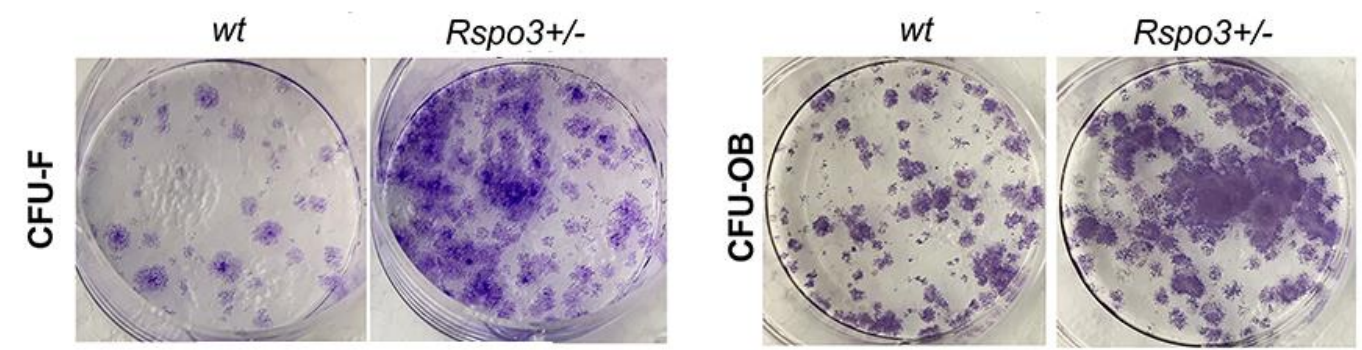

CFU-F
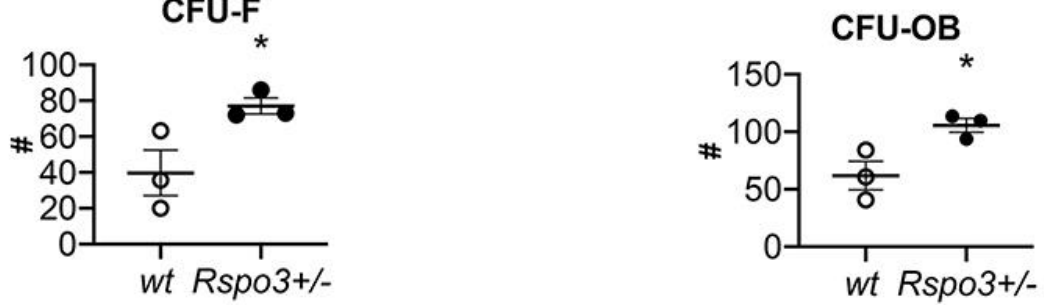

Figure 2. Rspo3 haplo-insufficiency increases the \% of osteoprogenitors. a) Representative images of FACS analysis. b) Quantification of the $\%$ of Lin ${ }^{-C} 445{ }^{-} \mathrm{Cd} 31^{-} \mathrm{CD} 51^{+} \mathrm{Sca}{ }^{+}$cells in $w t$ and $R s p o 3^{+/}$bone marrow. Data show all samples and the mean $\pm \operatorname{SEM}(n=10)^{*}=p<0.05$ by unpaired Student T-test. $\left.\mathbf{c}\right)$ Representative images of CFU-F and CFU-OB and quantification in wt and $R s p o 3^{+-}$mice. Data show all samples and the mean $\pm \operatorname{SEM}(n=3){ }^{*}=p<0.05$ by unpaired Student T-test. 
Specific deletion of Rspo3 in cells of the osteoblast lineage mirrors the skeletal phenotype seen with global Rspo3 haplo-insufficiency.

To assess whether the effect on bone mass seen in Rspo3 haplo-insufficient mice was cellautonomous to cells of the $\mathrm{OB}$ lineage, we generated mice with deletion of $R$ spo 3 in the $\mathrm{OB}$ lineage (Rspo3 ${ }^{\mathrm{OB}}$ ) by crossing Rspo3 ${ }^{f / / f l}$ mice with an OB-specific Cre-transgenic mice (Runx2Cre) $(43,47)$. OB lineage-targeted deletion of $R s p o 3$ (Fig. 3a) mirrored the skeletal phenotype seen in $R s p o 3^{+/}$mice as indicated by a significant increase in BV $/ T V$ (females $p=0.017$, males $p<0.0001$ ), MAR (females $p=0.0034$, males $p<0.0001$ ), BFR/BS (females $p=0.0012$, males $p<0.0001)$ and $N . O b / B . P m ~(p=0.033$, males $\mathrm{p}=0.007)$ in $R s p o 3^{O B}$ compared to their control $\left(R s p o 3^{f}\right)$ male and female littermates. Once again there was no changes in OC parameters (Fig. 3b, 3c and Table S4). These findings indicate that the increase in bone formation and in bone mass results from a cell-autonomous effect of $R s p o 3$ insufficiency in OB progenitors. 

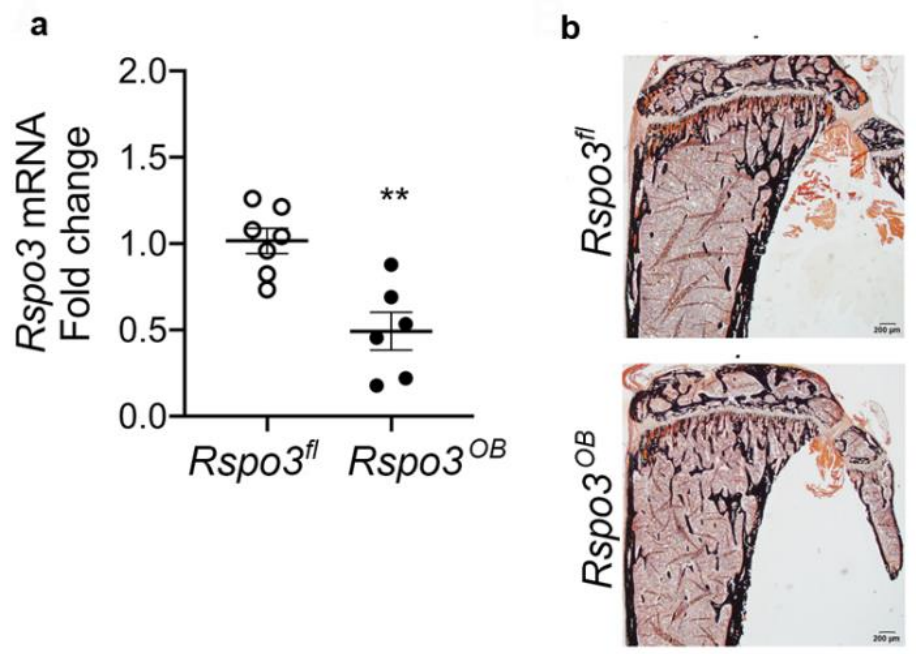

C
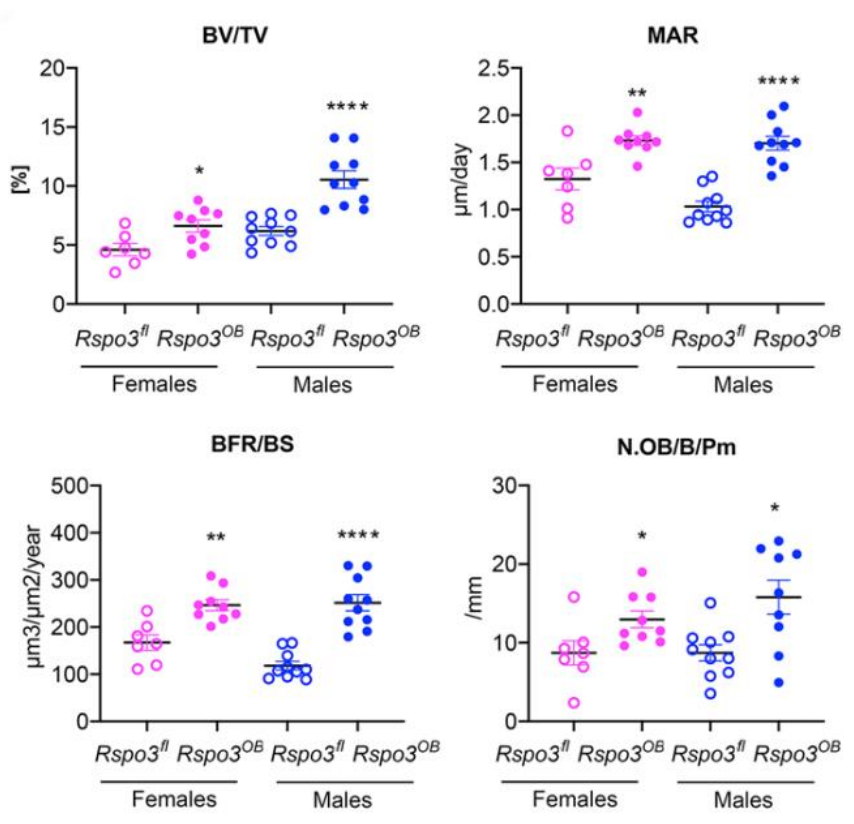

Figure 3. Skeletal phenotype of mice with Rspo3 targeted deletion in Runx2+ cells (Rspo3 ${ }^{\mathrm{OB}}$ ). a) $R s p o 3$ expression in marrow depleted long bones, showing deletion efficiency $(n=6-7)$. Data show all samples and are the mean \pm SEM ${ }^{* *} \mathrm{p}=0.0019$ by Student T-test. b) Representative images of Von Kossa

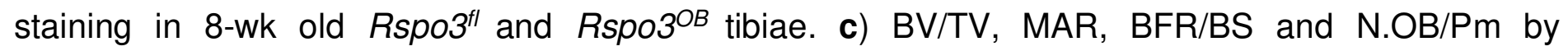
histomorphometric analysis Rspo3 ${ }^{f l}$ and Rspo3 ${ }^{O B}$ females and males $(n=7-10)$. Data show all samples and the mean \pm SEM ${ }^{*}=p<0.05,{ }^{* *}=p<0.005,{ }^{* * * *}=p<0.0001$ compared to the correspondent $R s p o 3^{f l}$ group by unpaired Student T-test. Open circles $=R s p o 3^{f l}$ and filled circles $=R s p o 3^{O B}$ 


\section{Rspo3 haplo-insufficiency and deletion lead to $\beta$-catenin stabilization.}

348 The above results raised the question of how reduction in Rspo3, classically considered a potentiator

349 of canonical Wnt signaling, leads to increased bone formation and trabecular bone mass. To address

350 this question, we first looked at the status of the Wnt signaling pathway in Rspo3 haplo-insufficiency.

351 Given the observed increase in OB progenitors in the bone marrow of Rspo3 ${ }^{+/}$mice (Fig. 2), and the

352 findings that the trabecular bone is the main compartment affected by Rspo3 haplo-insufficiency we

353 determined the level of Wnt signaling activation in Rspo3 haplo-insufficient bone marrow MSCs

354 (BMSCs) $(p=0.04)$. Surprisingly, but consistent with the observations on bone formation, Rspo3 haplo-

355 insufficiency led to a remarkable increase in the expression of known canonical Wnt target genes Axin2 $356(p=0.002)$ and Tcf-1 $(p=0.002)$, and increased active $\beta$-catenin levels ( $p=0.0005)$ (Fig. $4 a$ and $4 b)$. In 357 addition, Runx2 expression was also significantly increased in Rspo3 ${ }^{+/}$BMSCs ( $\left.\mathrm{p}=0.04\right)$ (Fig. 4a).

358 Thus, surprisingly but consistent with the bone and OB phenotypes, Rspo3 haplo-insufficiency leads to 359 activation of canonical Wnt signaling, which in turn results in increased trabecular bone formation and 360 bone mass. 

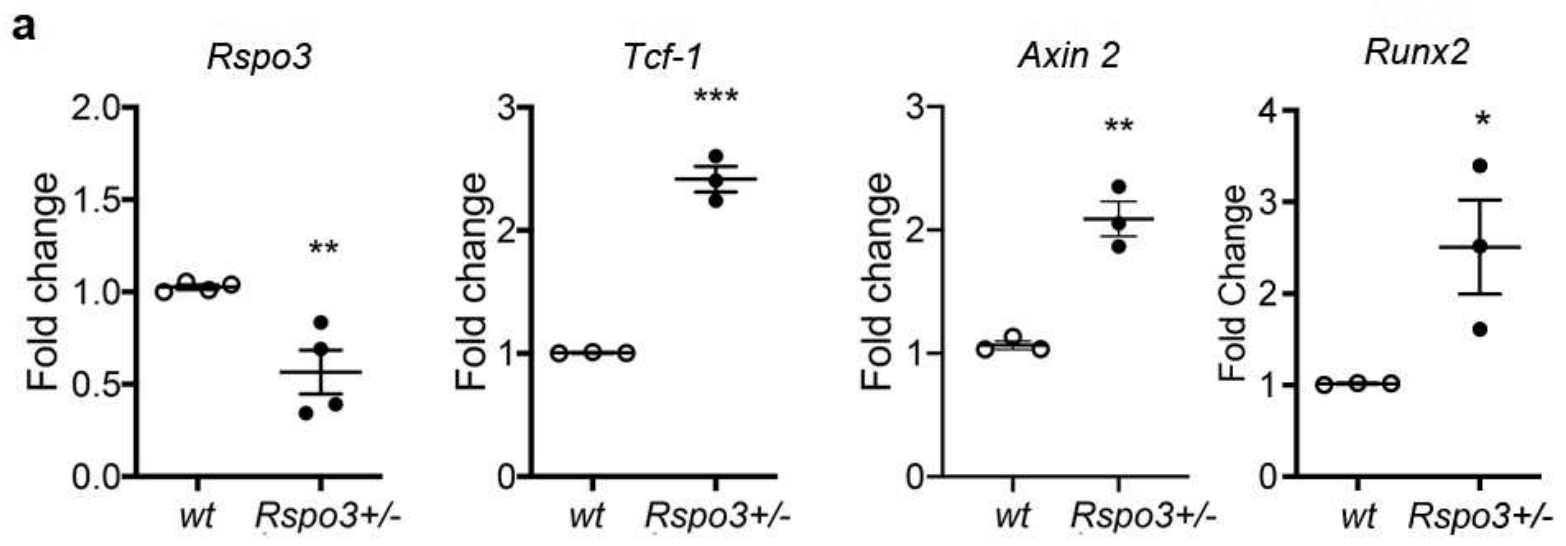

b

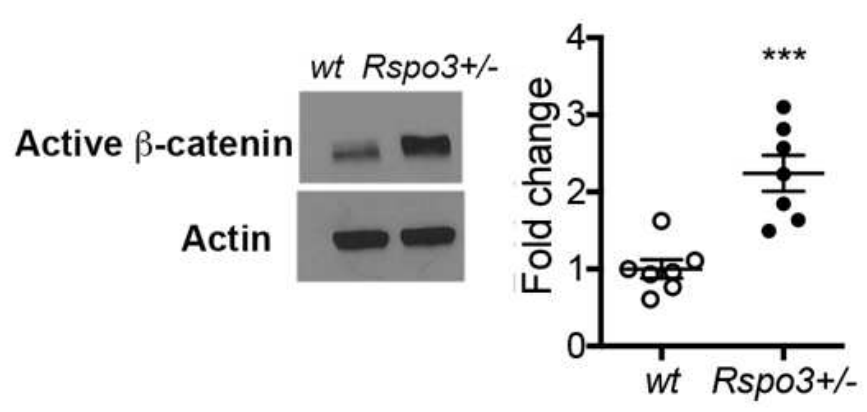

Figure 4. Rspo3 haplo-insufficiency leads to Wnt signaling activation in vitro. a) Expression of Rspo3, Runx2 and selected Wnt target genes in BMSCs $(n=3-4)$. Data show all samples and the mean \pm SEM. b) Representative images and quantification of active $\beta$-catenin by Western analysis in BMSC isolated from wt and $R$ spo $3^{+/}$mice $(\mathrm{n}=7) .{ }^{*} \mathrm{p}<0.05,{ }^{* *} \mathrm{p}<0.005,{ }^{* * *} \mathrm{p}<0.0005$ by unpaired Student T-test. 
To exclude any function of the remaining Rspo3 on canonical Wnt signaling in the $R s p o 3^{+/}$mice and cells, we generated Rspo3/- mouse embryonic fibroblasts (MEFs) at E9.5, before embryonic lethality $(24,27)$. As shown by several groups $(7,8,12,29)$, we confirmed that while Rspo3 does not activate Wnt signaling by itself, it potentiates exogenous Wnt3a action in wt MEFs as indicated by the Tcf-1/Lef luciferase reporter assay (Fig. 5a). Similar to what is observed in Rspo3 haplo-insufficient BMSCs, Rspo3 deficiency $(p<0.0001)$ led to a marked increase in the expression of the canonical Wnt target genes Tcf-1 $(p<0.0001)$ and Axin2 $(p=0.0017)$ at steady-state (Fig. $5 b)$ as well as to a significant increase in the levels of pLrp6, activated $\beta$-catenin and Tcf-1 (Fig 5c). Accordingly, TOPflash reporter activity was significantly increased in Rspo3 null MEFs compared to wt MEFs at steady state and further increased by Wnt3a treatment (Fig. 6d). Similarly, upon Wnt3a treatment, Axin2 and Tcf-1 expression as well as pLrp6 and activated $\beta$-catenin levels, were increased in the absence of Rspo3 ( Fig. 5c-d). Thus, these findings confirm that haplo-insufficiency and absence of Rspo3 in BMSCs and MEFs respectively, lead to $\beta$-catenin stabilization and enhancement of $\beta$-catenin-dependent signaling. We then explored the mechanisms by which this might occur. 
a

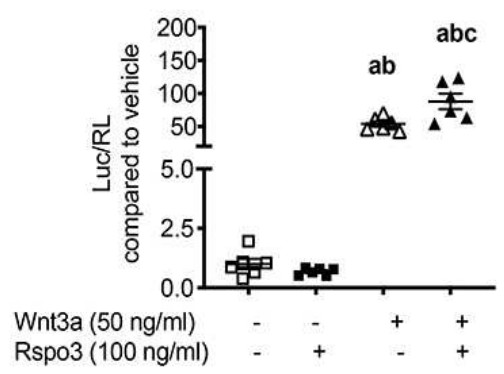

b

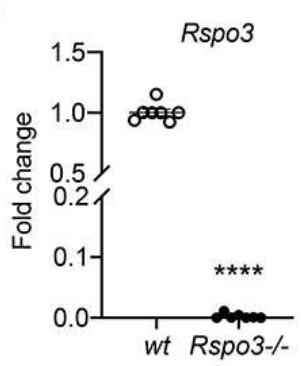

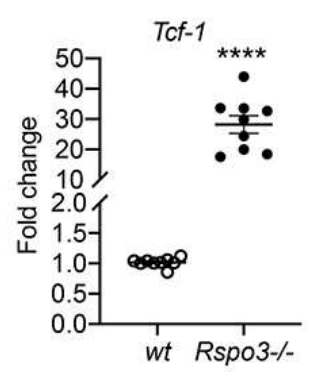

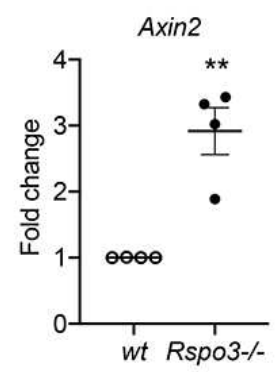

C

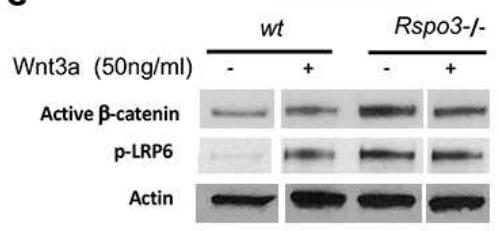

Wnt3a (50ng/ml)

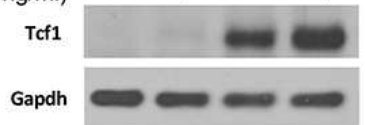

Active $\beta$-catenin

p-Lrp6

Tcf-1

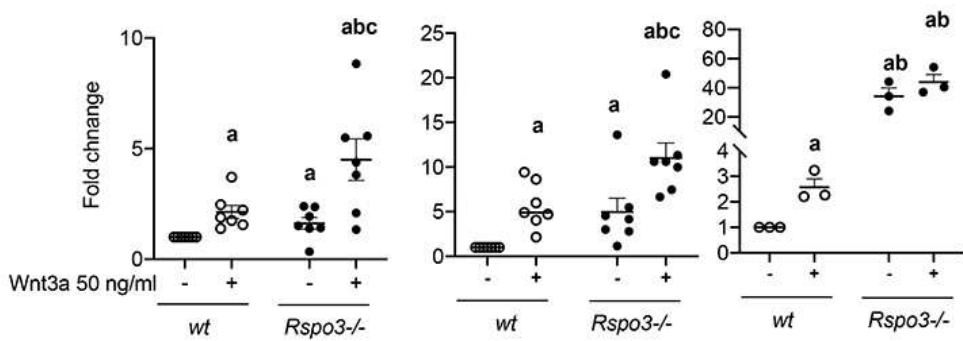

d

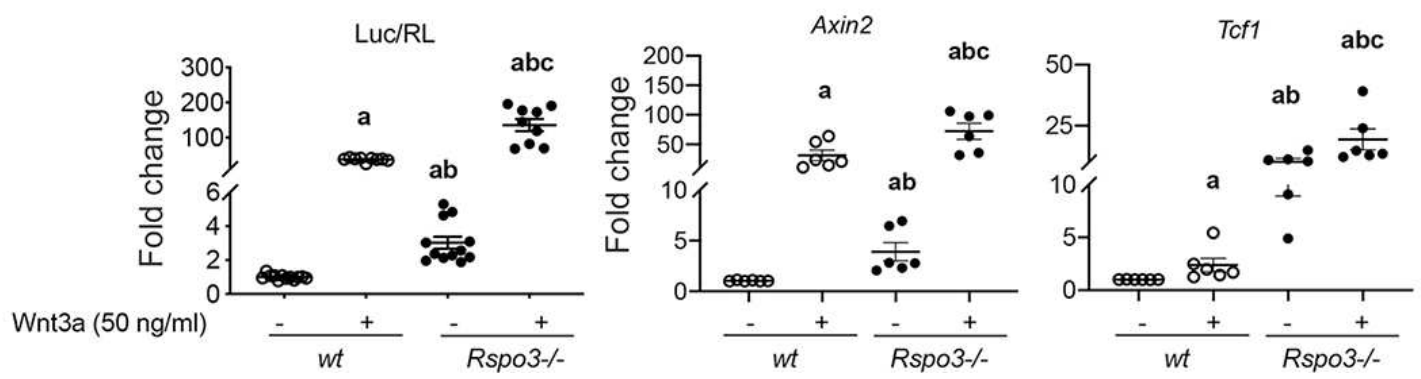

415 Figure 5. Rspo3 deletion leads to Wnt signaling activation in vitro. a) Luciferase assay in wt MEFs 416 treated w/wo Wnt3a and Rspo3 $(n=5)$. Data show all samples and the mean \pm SEM, $a=p<0.05$ vs vehicle wt, $b=p<0.05$ vs Rspo3 treated wt and $c=p<0.05$ vs Wnt3a treated wt by Two-Way ANOVA followed by Fisher's LSD test. b) Expression of Wnt target genes in wt and Rspo-/ MEFS (n=3-9). Data show all samples and the mean \pm SEM. ${ }^{* *} p<0.005,{ }^{* * *} p<0.0001$ by unpaired Student T-test. c) Representative images and quantification of active $\beta$-catenin, pLrp6 and Tcf-1 by Western analysis in wt and $R s p o^{--}$MEFs treated w/wo Wnt3a $(\mathrm{n}=3-7)$. Data show all samples and the mean \pm SEM. d) Luciferase assay and Wnt target gene expression in wt and Rspo-/- MEFs treated w/wo Wnt3a (n=611). Data show all samples and the mean \pm SEM $a=p<0.05$ vs vehicle $w t, b=p<0.05$ vs Wnt3a-treated wt and $\mathrm{c}=\mathrm{p}<0.05$ vs Wnt3a treated $R s p o 3^{--}$by Two-Way ANOVA followed by Fisher's LSD test. 
Rspo3 haplo-insufficiency and deletion impair Dkk1-Wnt inhibitory activity.

Activation of canonical Wnt signaling results from changes in endogenous activators and/or inhibitors levels and/or their activity. Interestingly, we found that Wnt3a significantly decreases the expression of Rspo3 in wt MEFs $(\mathrm{p}=0.006)$, whereas it is significantly increased by Dkk1 $(\mathrm{p}=0.023)$ (Fig. 6a). This raised the possibility that Rspo3 participates in a feedback loop that tones down or balances canonical Wnt activity. As shown in Figure 6b, we found that the ability of Dkk1 to block Wnt3a-dependent activation of canonical Wnt signaling was significantly impaired in the absence of Rspo3: whereas in $w t \mathrm{MEFs}, 50 \%$ reduction in the reporter activity was achieved by $50 \mathrm{ng} / \mathrm{mL}$ Dkk1, a dose of $400 \mathrm{ng} / \mathrm{mL}$ Dkk1 (8x higher) was needed to obtain the same level of inhibition in Rspo3 null MEFs (Fig. 6b). A similar difference was also observed in pLrp6 and $\beta$-catenin protein levels (Fig. 6c). To determine whether this relationship between Rspo3 levels and Dkk1 efficacy was also happening in vivo, we crossed $\mathrm{Rspo}^{+/-}$mice with mice expressing high levels of Dkk1 in OBs (Dkk1-Tg mice), which exhibit impaired canonical Wnt signaling and low trabecular bone mass due to decreased bone formation (42, 49). Supporting our in vitro data, Rspo3 haplo-insufficiency counteracted the effect of Dkk1 overexpression on the skeleton in vivo. Histomorphometric analysis showed that the low BV/TV and decreased bone formation parameters (MAR, BFR/BS and N.Ob/B.pm) seen in Dkk1-Tg mice were significantly rescued by Rspo3 haplo-insufficiency (Fig. 6d-e and Table S5). 
a

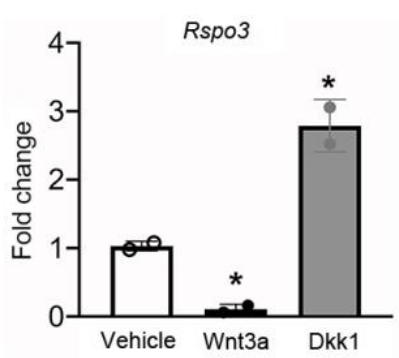

b

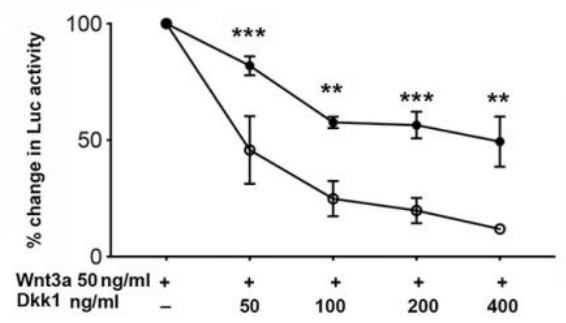

447

448

449

450

451

452

453

454

455

456

457

458

459

460

461

462

463

464

465

466

467
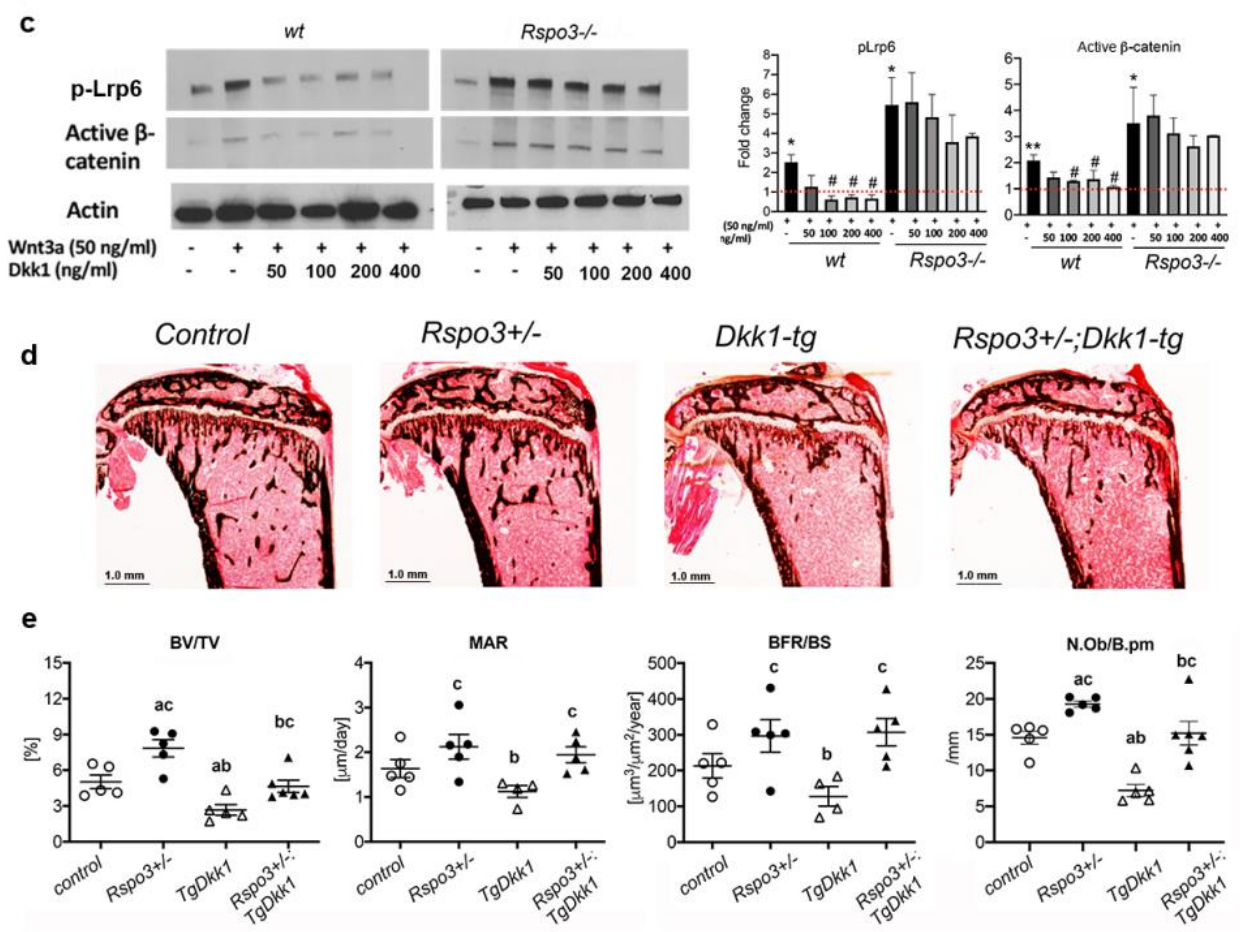

Figure 6. Rspo3 deletion/ haplo-insufficiency impairs Dkk1 efficacy. a) regulation of Rspo3 by Wnt3a and Dkk1 in wt MEFs ( $n=2)$ Data are the mean \pm SD. ${ }^{*} p<0.05$. b) Luciferase assay in $w t$ and $R s p o^{-/}$ MEFs treated $w / w o ~ W n t 3 a$ and increasing doses of Dkk1 $(n=3-4)$. Data are the mean $\pm S E M{ }^{* *} p<0.005$, ${ }^{* * *}<p<0.0005$ compared to vehicle same genotype by Student-t test. c) Representative images and quantification of active $\beta$-catenin and pLrp6 by Western analysis in wt and Rspo3- MEFs treated w/wo Wnt3a and increasing doses of Dkk1 $(n=3)$. Data are the mean \pm SEM ${ }^{*} p<0.05,{ }^{* *} p, 0.005$ vs wt vehicle, \# = vs Wnt3a-treated same genotype by Student-t test. d) Representative images of Von Kossa staining in 6-wk old female mice. e) BV/TV, MAR, BFR/BS and N.Ob./B.pm by histomorphometric analysis in females $(n=5-6)$. Data show all samples and the mean $\pm S E M a=p<0.05$ compared to control mice, $\mathrm{b}=\mathrm{p}<0.05$ compared to Rspo3 ${ }^{+/}$mice, $\mathrm{c}=\mathrm{p}<0.05$ compared to $D k k 1-\mathrm{Tg}$ mice by two-Way ANOVA followed by Fisher's LSD test. 
Since both Rspo3 haplo-insufficiency and its deletion lead to $\beta$-catenin stabilization, we asked whether Rspo3 might regulate other signaling pathways which in turn can stabilize $\beta$-catenin, stimulating osteoblastogenesis and counteracting Dkk1 efficacy. It has been proposed that Rspo3 binding to Lgr4 inhibits Erk phosphorylation (pErk) $(23,41,50)$. We therefore investigated Erk signaling, known to activate Wnt signaling and to regulate OB differentiation and bone mass (51-54), in our model. Rspo3 deficiency led to a clear and significant increase in pErk basal levels (Fig. 7a). Although in wt cells the specific Erk inhibitor U0126 significantly decreased both the basal and the Wnt3a-dependent increase in $p E r k$, it did not significantly affect active $\beta$-catenin levels. In contrast, inhibition of $p E r k$ in Rspo3 ${ }^{-/}$cells led to a significant decrease in active $\beta$-catenin levels in both steady state and Wnt3astimulated cultures. A similar effect was also seen for the levels of pLrp6 (Fig. 7a). Confirming these findings, the increase in the expression of the canonical Wnt signaling target genes Tcf1 and Axin2 was also partially rescued by blocking Erk signaling in Rspo3 null MEFs (Fig. 7b). Thus, the stabilization of $\beta$-catenin we observe in the absence of Rspo3 is due, at least in part, to activation of the Erk pathway. 
a
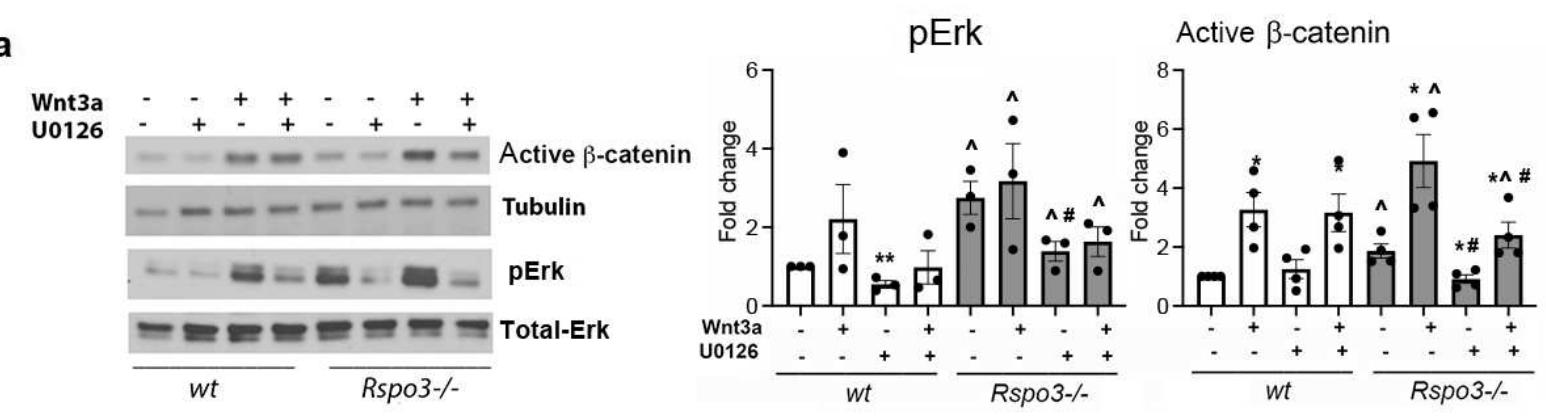

488
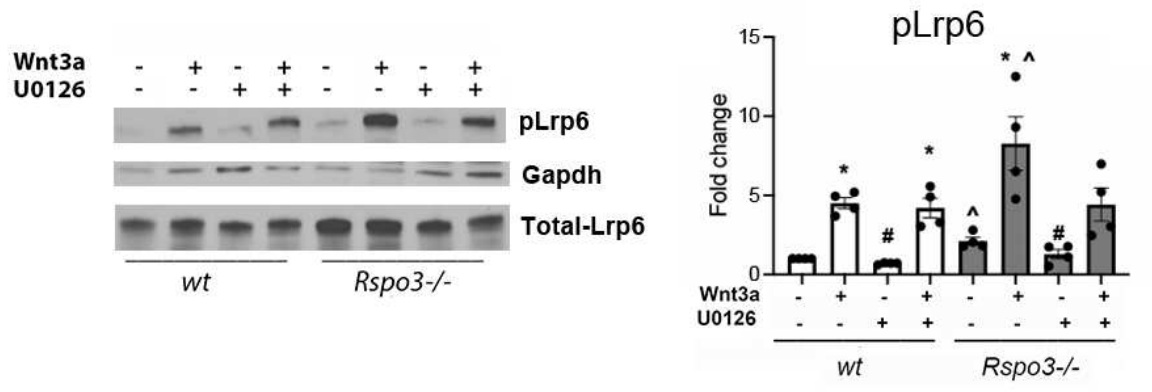

b

Tcf-1

Axin2
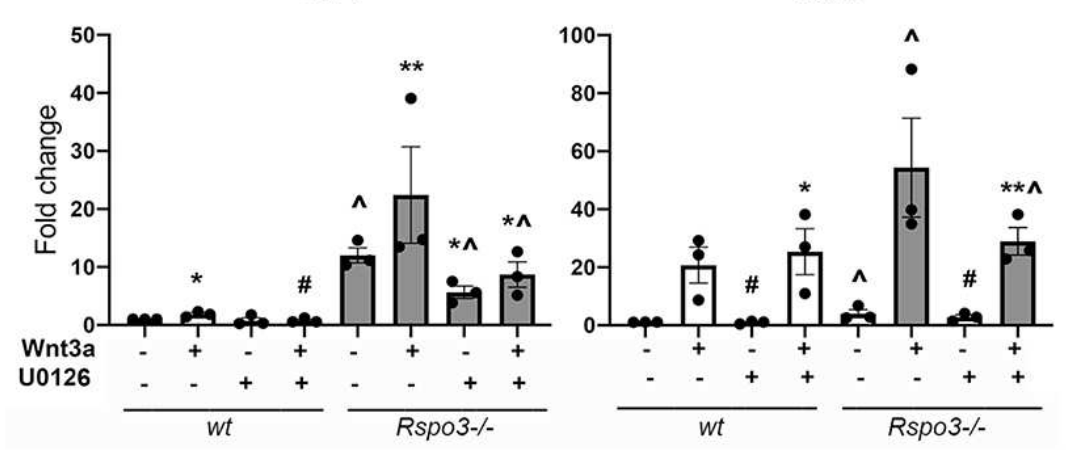

Figure 7. Erk signaling is involved in the Wnt signaling activation seen in the absence of Rspo3. a) Representative images and quantification of $\mathrm{pERK}$, active $\beta$-catenin and pLrp6 by western analysis in $w t$ and Rspo3-- MEFs treated w/wo w/wo Wnt3a and U0126. b) Expression of Wnt target genes in wt and Rspo3 ${ }^{--}$MEFs treated w/wo Wnt3a and U0126. Data show all samples and the mean \pm SEM $(n=3-$ 4) ${ }^{*} p<0.05,{ }^{* *} p, 0.005$ vs vehicle of the same genotype, ${ }^{\wedge}=p<0.05$ vs wt vehicle and $\#=p<0.05$ vs Wnt3a-treated same genotype by unpaired Student-t test. 


\section{Discussion}

Wnt signaling is central to skeletal development and homeostasis in health and disease (3). Understanding the biological mechanisms by which this signal operates is therefore of both scientific and clinical interest. R-Spondins, classically considered as positive modulators of Wnt signaling, play an important role in normal development of several tissues and organs including bone, and are implicated in human diseases $(8,9,11-13)$. Investigating further their exact function therefore holds therapeutic potential. Our results clearly demonstrate, through several independent lines of genetic in vivo and in vitro experiments, that, counter-intuitively, decreasing Rspo3 results in canonical Wnt and Erk signaling activation, increased trabecular bone formation and high bone mass, mainly driven by increased number of $\mathrm{OB}$ progenitors and $\mathrm{OBs}$ as well as an increase in their bone forming activity, with no effect on OC number. The findings that cortical bone is not significantly affected by Rspo3 haploinsufficiency underline the biologic complexity of Wnt signaling in bone homeostasis and support several findings that trabecular and cortical bone are differentially regulated. The emerging hypothesis is that the interplay between different signaling cascades ultimately induces specific and distinct responses in cortical and trabecular bone $(47,55-57)$. These compartment-specific responses may also be associated with different populations of cells present in the trabecular and the cortical bone microenvironment and to the differential expression levels of receptors and co-receptors as well as of agonists and antagonists that balance Wnt signaling activity. Interestingly, in this context are the findings that Sost levels in cortical bone were not altered by Rspo3 haploinsufficiency (data not shown), which could explain the lack of changes in the cortex. Thus, our studies reveal a novel and unexpected function of Rspo3 on the Wnt signaling machinery in trabecular bone homeostasis. This might have implications for our understanding of the multi-faceted aspects of Wnt signaling regulation of skeletal homeostasis, and possibly reveal novel ways to increase bone mass in patients.

Despite the fact that the four Rspos display high structural similarity and sequence homology, they display differential expression profiles (32) and have unique and distinct functions $(8,11,58)$. Studies in mice have shown that during embryonic development Rspo3 is highly expressed in the skeleton (32). 
We have recently reported that $R s p o 3$ is expressed in osteoprogenitors in the craniofacial complex (33) in both mice and zebrafish. However, rspo3 disruption in zebrafish has only mild effects on larval craniofacial cartilage skeleton (33) and in mice its haplo-insufficiency does not appear to affect craniofacial development. Human GWA studies have shown that RSPO3 might be specifically involved in bone metabolism due to the strong association between RSPO3 common variants and bone mineral density $(34,35,37-39)$. Whether these variants lead to RSPO3 gain of- or loss of- function is however not known. Rspos are considered to be co-activators of Wnt signaling $(3,7,29)$. Accordingly, treatment with Rspos has been reported to have a positive effect on osteogenesis $(10,28,40)$, such that decreasing its expression levels should have a negative impact on skeletal homeostasis. In contrast, we show here that Rspo3 haplo-insufficiency has an anabolic effect on bone. Importantly, targeted deletion of Rspo3 in the OB lineage in mice mimicked the skeletal phenotype seen with Rspo3 global haplo-insufficiency, revealing an OB lineage cell-autonomous effect of Rspo3 in the regulation of skeletal homeostasis.

In vitro studies have demonstrated that overexpression of and treatment with Rspo1 or Rspo2 enhance Wnt ligand-mediated OB differentiation $(9,10,28)$. Nonetheless, our in vitro, ex vivo and in vivo studies demonstrate that Rspo3 haplo-insufficiency and its deletion result in canonical Wnt signaling activation. As discussed later, and although paradoxical, these two observations are not mutually exclusive or discrepant. The literature and our own in vitro studies indeed confirm that Rspo3 is, as expected, a co-activator of canonical Wnt signaling in the Topflash assay, potentiating Wnt3adependent activation of canonical Wnt signaling in cellular assays ((58) and Fig. 5). However, the expression of canonical Wnt target genes and the levels of pLrp6 and activated $\beta$-catenin were markedly increased in Rspo3 haplo-insufficient BMSCs and in Rspo3-null MEFs, indicating that, counter-intuitively, in bone the decrease or absence of Rspo3 activates mechanisms that favor $\beta$ catenin-dependent signaling. 
The findings that $R s p o 3$ is strongly repressed by Wnt3a and increased by Dkk1, suggest that Rspo3 may in fact provide a negative feedback-loop helping to balance canonical Wnt activity. We found that Dkk1 efficacy in blocking Wnt3a-dependent activation of canonical Wnt signaling is significantly impaired in the absence of Rspo3, suggesting that the effect of Rspo3 on Dkk1 efficacy and expression represents a specific regulatory mechanism. Additionally, our finding that Rspo3 haplo-insufficiency antagonizes the inhibition of bone formation induced by OB-targeted expression of Dkk1 confirms in vivo the fact that Rspo3 haplo-insufficiency counteracts Dkk1 function. The question is whether this occurs at the cell surface or is the result of intracellular changes in alternative pathways regulated by Rspo3. Our findings that the Erk signaling pathway is activated and the basal level of pLrp6 enhanced by Rspo3 depletion suggests the possibility that the activation of the Wnt signaling pathway results from intra-cellular changes.

Our data and that of others (23) suggest that there are alternate Rspo3-mediated signaling mechanisms, separate from the Fzd/Lrp/ $\beta$-catenin Wnt pathway, including the Wnt/PCP signaling (14, 15 ) and that these events can in turn regulate Wnt signaling intra-cellularly. Indeed, $\beta$-catenin can be stabilized independent of the proximal activation of the canonical Wnt signaling machinery through changes in other signaling pathways $(3,54,59)$.

We show here that deletion of Rspo3 enhances Erk signaling which, in turn, stabilizes $\beta$-catenin independent of the canonical Wnt signaling receptor complex as shown by the significant increase in Erk phosphorylation observed in the absence of Rspo3. In turn, this activation of Erk signaling, promotes pLrp6 and $\beta$-catenin stabilization and has a positive effect on OB differentiation $(51,53,54)$. Our finding that the increase in Wnt signaling activation seen in the absence of $R s p o 3$ is abrogated by blocking Erk signaling strongly suggests that the activation of Erk signaling associated with Rspo3 deficiency is responsible, at least in part, for the observed Wnt signaling activation.

In agreement with our findings, in vitro studies have reported that Rspo3 silencing leads to increased OB differentiation of human adipose-derived stem cells by activating the Erk signaling downstream of 
Lgr4 (41). Importantly, although Lgrs function as receptors for Rspos, and Rspos/Lgrs interactions enhance Wnt signaling by inducing the clearance of Rnf43 and Znrf3 $(16,17,60)$, there is strong evidence that Rspos/Lgrs interaction can also activate distinct signaling cascades that can affect bone, including the cAMP/PKA/Creb signaling pathway in Lgr4 null mice (61) and the Erk signaling cascade $(41,62-64)$.

Based on our observations, we propose that Rspo3 has a dual mode of action to regulate canonical Wnt signaling and bone formation. This duality is based on the regulation of two distinct signaling cascades and their crosstalk: Rspo3 functions via both the Lgr/Rnf43/Znrf3 and the Lgr/Erk axes, and while activation of the Lgr/Rnf43/Znrf3 axis boosts Wnt signaling strength by the membrane clearance of Rnf43/Znrf3 and subsequent stabilization of Fzd receptors, binding of Rspo3 to Lgr impairs Erk signaling likely due to the membrane clearance of the Lgr receptors, preventing Erk signaling activation and further stabilization of $\beta$-catenin (Fig. 8). Thus, haplo-insufficiency and deletion of Rspo3 would dampen Wnt signaling at the cell surface by preventing the Rnf43/Znrf3 effects while enhancing pLrp6 and $\beta$-catenin stabilization intracellularly, via Erk phosphorylation, which has a more potent effect and overcompensates the decrease in Rspo3-dependent proximal Wnt activation in OBs and their progenitors. Because activation of the Lgr/Rnf43/Znrf3 cascade is not exclusively dependent on Rspo3, deletion of Rspo3 would only hinder canonical Wnt signaling partially. In contrast, lack of Rspo3 promotes the Lgr/Erk cascade, which leads to Erk signaling activation, which in turn not only enhances $\beta$-catenin stabilization (Fig. 8) but also regulates OB differentiation and bone formation. This model can also explain the observed loss of Dkk1 efficacy in inhibiting Wnt signaling: the Erk-dependent stabilization of $\beta$-catenin being independent of proximal Wnt receptor activation, Dkk1 cannot dampen the activation of downstream events as they are independent of the LRP5/6-Fzd receptor complex. 

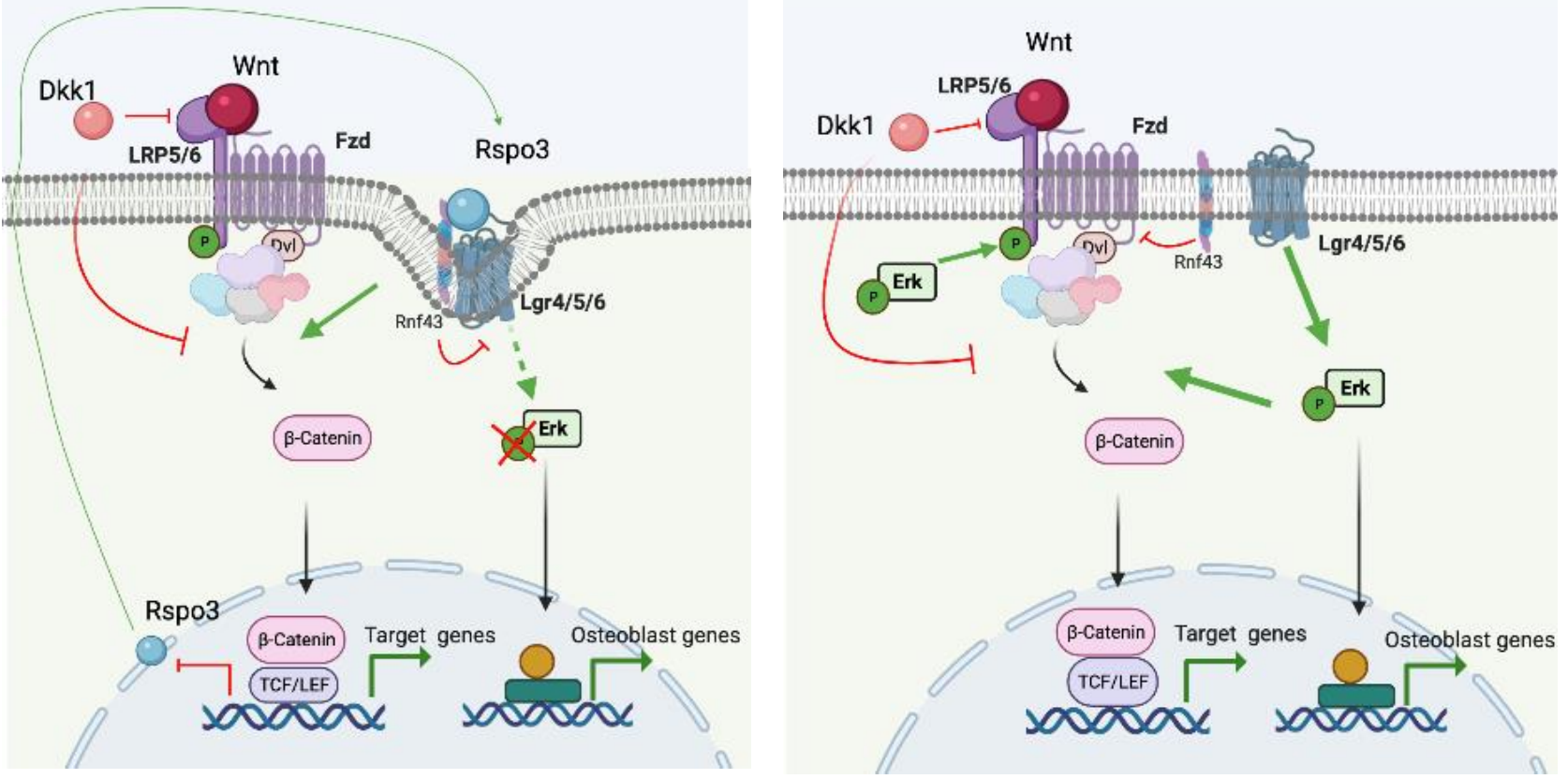

Figure 8. Proposed model. Rspo3 has a dual mode of action to regulate canonical Wnt signaling and thereby bone formation. This duality is based on the regulation of two distinct signaling cascades and their crosstalk: Rspo3 functions via both the Lgr/Rnf43/Znrf3 and the Lgr/Erk axes. In the presence of Rspo3, the Rspo3/Lgr/Rnf43/Znrf3 axis boosts Wnt signaling strengths by the membrane clearance of Rnf43/Znrf3 and subsequent stabilization of Fzd receptors. In addition, binding of Rspo3 to Lgr impairs Erk signaling likely due to the membrane clearance of the Lgr/Rnf43/Znrf3 receptors, preventing Erk signaling activation. Deletion of Rspo3 would dampen Wnt signaling at the cell surface by preventing the Rnf43/Znrf3 effects while promoting Erk activation downstream of Lgr receptors in turn enhancing Lrp5/6 phosphorylation and $\beta$-catenin stabilization intracellularly, which has a more potent effect and overcompensates the decrease in Rspo3-dependent proximal Wnt activation in osteoblasts and their progenitors. Figure created with Biorender. 
Supporting the fact that Rspo3 can also regulate Wnt-independent pathways, a recent study has suggested that Rspo3 acts as an antagonist to BMPR1A, inhibiting BMP signaling during development (23). Thus, our observations may be due, at least in part, to changes (activation) in BMP signaling, which in turn could lead to the observed increase in pErk (50). Although this remains a possibility, it seems unlikely. First, in contrast to our observations here, BMP activation in the adult skeleton has been linked to activation of non-canonical Wnt signaling, increased Sost expression and bone resorption $(57,65)$. Second, several studies have shown that activation of BMP signaling in the osteoblast lineage has a negative impact on bone formation and bone mass (66-69).

In conclusion, our studies suggest that Rspo3 regulates bone formation through its interaction not only with the Wnt receptor machinery but also with other signaling pathways that affect $\beta$-catenin stability. Consequently, if its deletion removes a co-activator of Wnt signaling, potentially decreasing bone formation, it also promotes Erk signaling activation, increasing $\beta$-catenin stability sufficiently to enhance bone formation and increase bone mass. Furthermore, because Rspo3 depletion increases Dkk1 and Dkk1 increases Rspo3 expression, this study reveals also a novel feedback Wnt signaling regulatory loop. These findings have important implications for understanding the pleiotropic functions of Rspos and Wnt signaling in skeletal homeostasis and reveal alternative mechanisms to increase bone mass.

\section{Reference}

1. Clevers H, Nusse R. Wnt/beta-catenin signaling and disease. Cell. 2012;149(6):1192-205. Epub 2012/06/12. doi: 10.1016/j.cell.2012.05.012. PubMed PMID: 22682243.

2. Nusse R, Clevers H. Wnt/beta-Catenin Signaling, Disease, and Emerging Therapeutic Modalities. Cell. 2017;169(6):985-99. Epub 2017/06/03. doi: 10.1016/j.cell.2017.05.016. PubMed PMID: 28575679.

3. Baron R, Kneissel M. WNT signaling in bone homeostasis and disease: from human mutations to treatments. Nat Med. 2013;19(2):179-92. doi: 10.1038/nm.3074. PubMed PMID: 23389618. 
4. Gori F, Baron, R. Wnt signaling in skeletal homeostasis and diseases. Osteoporosis, Fifth Edition Academic Press Elsevier. 2021:257-79.

5. Huybrechts Y, Mortier G, Boudin E, Van Hul W. WNT Signaling and Bone: Lessons From Skeletal Dysplasias and Disorders. Front Endocrinol (Lausanne). 2020;11:165. Epub 2020/04/25. doi: 10.3389/fendo.2020.00165. PubMed PMID: 32328030; PMCID: PMC7160326.

6. Baron R, Gori F, Leder BZ. Sclerostin Inhibition in the Treatment of Osteoporosis. Osteoporosis Pathophysiology and Clinical Management Editors: Leder BZ and Wein MN Springer Third Edition. 2020:375.

7. de Lau W, Peng WC, Gros P, Clevers H. The R-spondin/Lgr5/Rnf43 module: regulator of Wnt signal strength. Genes Dev. 2014;28(4):305-16. Epub 2014/02/18. doi: 10.1101/gad.235473.113. PubMed PMID: 24532711; PMCID: PMC3937510.

8. de Lau WB, Snel B, Clevers HC. The R-spondin protein family. Genome Biol. 2012;13(3):242. Epub 2012/03/24. doi: 10.1186/gb-2012-13-3-242. PubMed PMID: 22439850; PMCID: PMC3439965.

9. Knight MN, Hankenson KD. R-spondins: novel matricellular regulators of the skeleton. Matrix Biol. 2014;37:157-61. Epub 2014/07/02. doi: 10.1016/j.matbio.2014.06.003. PubMed PMID: 24980904.

10. Lu W, Kim KA, Liu J, Abo A, Feng X, Cao X, Li Y. R-spondin1 synergizes with Wnt3A in inducing osteoblast differentiation and osteoprotegerin expression. FEBS Lett. 2008;582(5):643-50. Epub 2008/02/05. doi: 10.1016/j.febslet.2008.01.035. PubMed PMID: 18242177.

11. Nagano K. R-spondin signaling as a pivotal regulator of tissue development and homeostasis. Jpn Dent Sci Rev. 2019;55(1):80-7. Epub 2019/05/03. doi: 10.1016/j.jdsr.2019.03.001. PubMed PMID: 31049116; PMCID: PMC6479641.

12. Raslan AA, Yoon JK. R-spondins: Multi-mode WNT signaling regulators in adult stem cells. Int J Biochem Cell Biol. 2019;106:26-34. Epub 2018/11/16. doi: 10.1016/j.biocel.2018.11.005. PubMed PMID: 30439551. 
13. Shi GX, Mao WW, Zheng XF, Jiang LS. The role of R-spondins and their receptors in bone metabolism. Prog Biophys Mol Biol. 2016;122(2):93-100. Epub 2016/05/31. doi: 10.1016/j.pbiomolbio.2016.05.012. PubMed PMID: 27237581.

14. Glinka A, Dolde C, Kirsch N, Huang YL, Kazanskaya O, Ingelfinger D, Boutros M, Cruciat CM, Niehrs C. LGR4 and LGR5 are R-spondin receptors mediating Wnt/beta-catenin and Wnt/PCP signalling. EMBO Rep. 2011;12(10):1055-61. Epub 2011/09/13. doi: 10.1038/embor.2011.175. PubMed PMID: 21909076; PMCID: PMC3185347.

15. Hao HX, Xie Y, Zhang Y, Charlat O, Oster E, Avello M, Lei H, Mickanin C, Liu D, Ruffner H, Mao X, Ma Q, Zamponi R, Bouwmeester T, Finan PM, Kirschner MW, Porter JA, Serluca FC, Cong F. ZNRF3 promotes Wnt receptor turnover in an R-spondin-sensitive manner. Nature. 2012;485(7397):195-200. Epub 2012/05/12. doi: 10.1038/nature11019. PubMed PMID: 22575959.

16. Ruffner H, Sprunger J, Charlat O, Leighton-Davies J, Grosshans B, Salathe A, Zietzling S, Beck V, Therier M, Isken A, Xie Y, Zhang Y, Hao H, Shi X, Liu D, Song Q, Clay I, Hintzen G, Tchorz J, Bouchez LC, Michaud G, Finan P, Myer VE, Bouwmeester T, Porter J, Hild M, Bassilana F, Parker CN, Cong F. R-Spondin potentiates Wnt/beta-catenin signaling through orphan receptors LGR4 and LGR5. PLoS One. 2012;7(7):e40976. Epub 2012/07/21. doi: 10.1371/journal.pone.0040976. PubMed PMID: 22815884; PMCID: PMC3397969.

17. Wang D, Huang B, Zhang S, Yu X, Wu W, Wang X. Structural basis for R-spondin recognition by LGR4/5/6 receptors. Genes Dev. 2013;27(12):1339-44. Epub 2013/06/13. doi: 10.1101/gad.219360.113. PubMed PMID: 23756652; PMCID: PMC3701189.

18. Xie Y, Zamponi R, Charlat O, Ramones M, Swalley S, Jiang X, Rivera D, Tschantz W, Lu B, Quinn L, Dimitri C, Parker J, Jeffery D, Wilcox SK, Watrobka M, LeMotte P, Granda B, Porter JA, Myer VE, Loew A, Cong F. Interaction with both ZNRF3 and LGR4 is required for the signalling activity of Rspondin. EMBO Rep. 2013;14(12):1120-6. Epub 2013/10/30. doi: 10.1038/embor.2013.167. PubMed PMID: 24165923; PMCID: PMC3981092. 
19. Lebensohn AM, Rohatgi R. R-spondins can potentiate WNT signaling without LGRs. Elife. 2018;7. Epub 2018/02/07. doi: 10.7554/eLife.33126. PubMed PMID: 29405118; PMCID: PMC5800842.

20. Szenker-Ravi E, Altunoglu U, Leushacke M, Bosso-Lefevre C, Khatoo M, Thi Tran H, Naert T, Noelanders R, Hajamohideen A, Beneteau C, de Sousa SB, Karaman B, Latypova X, Basaran S, Yucel EB, Tan TT, Vlaminck L, Nayak SS, Shukla A, Girisha KM, Le Caignec C, Soshnikova N, Uyguner ZO, Vleminckx K, Barker N, Kayserili H, Reversade B. RSPO2 inhibition of RNF43 and ZNRF3 governs limb development independently of LGR4/5/6. Nature. 2018;557(7706):564-9. Epub 2018/05/18. doi: 10.1038/s41586-018-0118-y. PubMed PMID: 29769720.

21. Rong X, Chen C, Zhou P, Zhou Y, Li Y, Lu L, Liu Y, Zhou J, Duan C. R-spondin 3 regulates dorsoventral and anteroposterior patterning by antagonizing Wnt/beta-catenin signaling in zebrafish embryos. PLoS One. 2014;9(6):e99514. Epub 2014/06/12. doi: 10.1371/journal.pone.0099514. PubMed PMID: 24918770; PMCID: PMC4053527.

22. Wu C, Qiu S, Lu L, Zou J, Li WF, Wang O, Zhao H, Wang H, Tang J, Chen L, Xu T, Sun Z, Liao W, Luo G, Lu X. RSPO2-LGR5 signaling has tumour-suppressive activity in colorectal cancer. Nat Commun. 2014;5:3149. Epub 2014/01/31. doi: 10.1038/ncomms4149. PubMed PMID: 24476626.

23. Lee H, Seidl C, Sun R, Glinka A, Niehrs C. R-spondins are BMP receptor antagonists in Xenopus early embryonic development. Nat Commun. 2020;11(1):5570. Epub 2020/11/06. doi: 10.1038/s41467020-19373-w. PubMed PMID: 33149137; PMCID: PMC7642414.

24. Aoki $M$, Mieda $M$, Ikeda $T$, Hamada $Y$, Nakamura $H$, Okamoto $H$. R-spondin3 is required for mouse placental development. Dev Biol. 2007;301(1):218-26. Epub 2006/09/12. doi: 10.1016/j.ydbio.2006.08.018. PubMed PMID: 16963017.

25. Neufeld S, Rosin JM, Ambasta A, Hui K, Shaneman V, Crowder R, Vickerman L, Cobb J. A conditional allele of Rspo3 reveals redundant function of $\mathrm{R}$-spondins during mouse limb development. Genesis. 2012;50(10):741-9. Epub 2012/05/23. doi: 10.1002/dvg.22040. PubMed PMID: 22610508. 
26. Ishii Y, Wajid M, Bazzi H, Fantauzzo KA, Barber AG, Blaydon DC, Nam JS, Yoon JK, Kelsell DP, Christiano AM. Mutations in R-spondin 4 (RSPO4) underlie inherited anonychia. J Invest Dermatol. 2008;128(4):867-70. Epub 2007/09/07. doi: 10.1038/sj.jid.5701078. PubMed PMID: 17805348.

27. Kazanskaya O, Ohkawara B, Heroult M, Wu W, Maltry N, Augustin HG, Niehrs C. The Wnt signaling regulator R-spondin 3 promotes angioblast and vascular development. Development. 2008;135(22):3655-64. Epub 2008/10/10. doi: 10.1242/dev.027284. PubMed PMID: 18842812.

28. Knight MN, Karuppaiah K, Lowe M, Mohanty S, Zondervan RL, Bell S, Ahn J, Hankenson KD. Rspondin-2 is a Wnt agonist that regulates osteoblast activity and bone mass. Bone Res. 2018;6:24. Epub 2018/08/23. doi: 10.1038/s41413-018-0026-7. PubMed PMID: 30131881; PMCID: PMC6089978 Skelegen. The remaining authors declare no competing interests.

29. Park S, Cui J, Yu W, Wu L, Carmon KS, Liu QJ. Differential activities and mechanisms of the four R-spondins in potentiating Wnt/beta-catenin signaling. J Biol Chem. 2018;293(25):9759-69. Epub 2018/05/13. doi: 10.1074/jbc.RA118.002743. PubMed PMID: 29752411; PMCID: PMC6016459.

30. Parma P, Radi O, Vidal V, Chaboissier MC, Dellambra E, Valentini S, Guerra L, Schedl A, Camerino G. R-spondin1 is essential in sex determination, skin differentiation and malignancy. Nat Genet. 2006;38(11):1304-9. Epub 2006/10/17. doi: 10.1038/ng1907. PubMed PMID: 17041600.

31. Wei Q, Yokota C, Semenov MV, Doble B, Woodgett J, He X. R-spondin1 is a high affinity ligand for LRP6 and induces LRP6 phosphorylation and beta-catenin signaling. J Biol Chem. 2007;282(21):15903-11. Epub 2007/04/03. doi: 10.1074/jbc.M701927200. PubMed PMID: 17400545. 32. Nam JS, Turcotte TJ, Yoon JK. Dynamic expression of R-spondin family genes in mouse development. Gene Expr Patterns. 2007;7(3):306-12. Epub 2006/10/13. doi: 10.1016/j.modgep.2006.08.006. PubMed PMID: 17035101.

33. Alhazmi N, Carroll SH, Kawasaki K, Woronowicz KC, Hallett SA, Macias Trevino C, Li EB, Baron R, Gori F, Yelick PC, Harris MP, Liao EC. Synergistic roles of Wnt modulators R-spondin2 and Rspondin3 in craniofacial morphogenesis and dental development. Sci Rep. 2021;11(1):5871. Epub 2021/03/14. doi: 10.1038/s41598-021-85415-y. PubMed PMID: 33712657; PMCID: PMC7954795. 
34. Duncan EL, Danoy P, Kemp JP, Leo PJ, McCloskey E, Nicholson GC, Eastell R, Prince RL, Eisman JA, Jones G, Sambrook PN, Reid IR, Dennison EM, Wark J, Richards JB, Uitterlinden AG, Spector TD, Esapa C, Cox RD, Brown SD, Thakker RV, Addison KA, Bradbury LA, Center JR, Cooper C, Cremin C, Estrada K, Felsenberg D, Gluer CC, Hadler J, Henry MJ, Hofman A, Kotowicz MA, Makovey J, Nguyen SC, Nguyen TV, Pasco JA, Pryce K, Reid DM, Rivadeneira F, Roux C, Stefansson K, Styrkarsdottir U, Thorleifsson G, Tichawangana R, Evans DM, Brown MA. Genome-wide association study using extreme truncate selection identifies novel genes affecting bone mineral density and fracture risk. PLoS Genet. 2011;7(4):e1001372. Epub 2011/05/03. doi: 10.1371/journal.pgen.1001372. PubMed PMID: 21533022; PMCID: PMC3080863.

35. Estrada K, Styrkarsdottir U, Evangelou E, Hsu YH, Duncan EL, Ntzani EE, Oei L, Albagha OM, Amin N, Kemp JP, Koller DL, Li G, Liu CT, Minster RL, Moayyeri A, Vandenput L, Willner D, Xiao SM, Yerges-Armstrong LM, Zheng HF, Alonso N, Eriksson J, Kammerer CM, Kaptoge SK, Leo PJ, Thorleifsson G, Wilson SG, Wilson JF, Aalto V, Alen M, Aragaki AK, Aspelund T, Center JR, Dailiana Z, Duggan DJ, Garcia M, Garcia-Giralt N, Giroux S, Hallmans G, Hocking LJ, Husted LB, Jameson KA, Khusainova R, Kim GS, Kooperberg C, Koromila T, Kruk M, Laaksonen M, Lacroix AZ, Lee SH, Leung PC, Lewis JR, Masi L, Mencej-Bedrac S, Nguyen TV, Nogues X, Patel MS, Prezelj J, Rose LM, Scollen S, Siggeirsdottir K, Smith AV, Svensson O, Trompet S, Trummer O, van Schoor NM, Woo J, Zhu K, Balcells S, Brandi ML, Buckley BM, Cheng S, Christiansen C, Cooper C, Dedoussis G, Ford I, Frost M, Goltzman D, Gonzalez-Macias J, Kahonen M, Karlsson M, Khusnutdinova E, Koh JM, Kollia P, Langdahl BL, Leslie WD, Lips P, Ljunggren O, Lorenc RS, Marc J, Mellstrom D, Obermayer-Pietsch B, Olmos JM, Pettersson-Kymmer U, Reid DM, Riancho JA, Ridker PM, Rousseau F, Slagboom PE, Tang NL, Urreizti R, Van Hul W, Viikari J, Zarrabeitia MT, Aulchenko YS, Castano-Betancourt M, Grundberg E, Herrera L, Ingvarsson T, Johannsdottir H, Kwan T, Li R, Luben R, Medina-Gomez C, Palsson ST, Reppe S, Rotter JI, Sigurdsson G, van Meurs JB, Verlaan D, Williams FM, Wood AR, Zhou Y, Gautvik KM, Pastinen T, Raychaudhuri S, Cauley JA, Chasman DI, Clark GR, Cummings SR, Danoy P, Dennison EM, Eastell R, Eisman JA, Gudnason V, Hofman A, Jackson RD, Jones G, Jukema JW, 
781 Khaw KT, Lehtimaki T, Liu Y, Lorentzon M, McCloskey E, Mitchell BD, Nandakumar K, Nicholson GC, Oostra BA, Peacock M, Pols HA, Prince RL, Raitakari O, Reid IR, Robbins J, Sambrook PN, Sham PC, Shuldiner AR, Tylavsky FA, van Duijn CM, Wareham NJ, Cupples LA, Econs MJ, Evans DM, Harris TB, Kung AW, Psaty BM, Reeve J, Spector TD, Streeten EA, Zillikens MC, Thorsteinsdottir U, Ohlsson C, Karasik D, Richards JB, Brown MA, Stefansson K, Uitterlinden AG, Ralston SH, loannidis JP, Kiel DP, Rivadeneira F. Genome-wide meta-analysis identifies 56 bone mineral density loci and reveals 14 loci associated with risk of fracture. Nat Genet. 2012;44(5):491-501. Epub 2012/04/17. doi: 10.1038/ng.2249. PubMed PMID: 22504420; PMCID: PMC3338864.

36. Lee DY, Kim H, Ku SY, Kim SH, Choi YM, Kim JG. Association between polymorphisms in Wnt signaling pathway genes and bone mineral density in postmenopausal Korean women. Menopause. 2010;17(5):1064-70. doi: 10.1097/gme.0b013e3181da4da3. PubMed PMID: 20613673.

37. Medina-Gomez C, Kemp JP, Estrada K, Eriksson J, Liu J, Reppe S, Evans DM, Heppe DH, Vandenput L, Herrera L, Ring SM, Kruithof CJ, Timpson NJ, Zillikens MC, Olstad OK, Zheng HF, Richards JB, St Pourcain B, Hofman A, Jaddoe VW, Smith GD, Lorentzon M, Gautvik KM, Uitterlinden AG, Brommage R, Ohlsson C, Tobias JH, Rivadeneira F. Meta-analysis of genome-wide scans for total body BMD in children and adults reveals allelic heterogeneity and age-specific effects at the WNT16 locus. PLoS Genet. 2012;8(7):e1002718. Epub 2012/07/14. doi: 10.1371/journal.pgen.1002718. PubMed PMID: 22792070; PMCID: PMC3390371 have declared that no other competing interest exist. 38. Richards JB, Rivadeneira F, Inouye M, Pastinen TM, Soranzo N, Wilson SG, Andrew T, Falchi M, Gwilliam R, Ahmadi KR, Valdes AM, Arp P, Whittaker P, Verlaan DJ, Jhamai M, Kumanduri V, Moorhouse M, van Meurs JB, Hofman A, Pols HA, Hart D, Zhai G, Kato BS, Mullin BH, Zhang F, Deloukas P, Uitterlinden AG, Spector TD. Bone mineral density, osteoporosis, and osteoporotic fractures: a genome-wide association study. Lancet. 2008;371(9623):1505-12. Epub 2008/05/06. doi: 10.1016/S0140-6736(08)60599-1. PubMed PMID: 18455228; PMCID: PMC2679414. 
39. Richards JB, Zheng HF, Spector TD. Genetics of osteoporosis from genome-wide association studies: advances and challenges. Nat Rev Genet. 2012;13(8):576-88. Epub 2012/07/19. doi: 10.1038/nrg3228. PubMed PMID: 22805710.

40. Zhu C, Zheng XF, Yang YH, Li B, Wang YR, Jiang SD, Jiang LS. LGR4 acts as a key receptor for R-spondin 2 to promote osteogenesis through Wnt signaling pathway. Cell Signal. 2016;28(8):9891000. Epub 2016/05/04. doi: 10.1016/j.cellsig.2016.04.010. PubMed PMID: 27140682.

41. Zhang M, Zhang P, Liu Y, Lv L, Zhang X, Liu H, Zhou Y. RSPO3-LGR4 Regulates Osteogenic Differentiation Of Human Adipose-Derived Stem Cells Via ERK/FGF Signalling. Sci Rep. 2017;7:42841. Epub 2017/02/22. doi: 10.1038/srep42841. PubMed PMID: 28220828; PMCID: PMC5318871.

42. Guo J, Liu M, Yang D, Bouxsein ML, Saito H, Galvin RJ, Kuhstoss SA, Thomas CC, Schipani E, Baron R, Bringhurst FR, Kronenberg HM. Suppression of Wnt signaling by Dkk1 attenuates PTHmediated stromal cell response and new bone formation. Cell Metab. 2010;11(2):161-71. Epub 2010/02/10. doi: 10.1016/j.cmet.2009.12.007. PubMed PMID: 20142103; PMCID: PMC2819982.

43. Rauch A, Seitz S, Baschant U, Schilling AF, Illing A, Stride B, Kirilov M, Mandic V, Takacz A, Schmidt-Ullrich R, Ostermay S, Schinke T, Spanbroek R, Zaiss MM, Angel PE, Lerner UH, David JP, Reichardt HM, Amling M, Schutz G, Tuckermann JP. Glucocorticoids suppress bone formation by attenuating osteoblast differentiation via the monomeric glucocorticoid receptor. Cell Metab. 2010;11(6):517-31. Epub 2010/06/04. doi: 10.1016/j.cmet.2010.05.005. PubMed PMID: 20519123.

44. Dempster DW, Compston JE, Drezner MK, Glorieux FH, Kanis JA, Malluche H, Meunier PJ, Ott SM, Recker RR, Parfitt AM. Standardized nomenclature, symbols, and units for bone histomorphometry: a 2012 update of the report of the ASBMR Histomorphometry Nomenclature Committee. J Bone Miner Res. 2013;28(1):2-17. Epub 2012/12/01. doi: 10.1002/jbmr.1805. PubMed PMID: 23197339; PMCID: PMC3672237.

45. Schepers K, Pietras EM, Reynaud D, Flach J, Binnewies M, Garg T, Wagers AJ, Hsiao EC, Passegue E. Myeloproliferative neoplasia remodels the endosteal bone marrow niche into a self- 
830 reinforcing leukemic niche. Cell Stem Cell. 2013;13(3):285-99. Epub 2013/07/16. doi:

831 10.1016/j.stem.2013.06.009. PubMed PMID: 23850243; PMCID: PMC3769504.

832

833

834

835

836

837

838

839

840

841

842

843

844

845

846

847

848

849

850

851

852

853

854

46. Chen K, Ng PY, Chen R, Hu D, Berry S, Baron R, Gori F. Sfrp4 repression of the Ror2/Jnk cascade in osteoclasts protects cortical bone from excessive endosteal resorption. Proc Natl Acad Sci

U S A. 2019;116(28):14138-43. Epub 2019/06/27. doi: 10.1073/pnas.1900881116. PubMed PMID: 31239337; PMCID: PMC6628642.

47. Moverare-Skrtic S, Henning P, Liu X, Nagano K, Saito H, Borjesson AE, Sjogren K, Windahl SH, Farman H, Kindlund B, Engdahl C, Koskela A, Zhang FP, Eriksson EE, Zaman F, Hammarstedt A, Isaksson H, Bally M, Kassem A, Lindholm C, Sandberg O, Aspenberg P, Savendahl L, Feng JQ, Tuckermann J, Tuukkanen J, Poutanen M, Baron R, Lerner UH, Gori F, Ohlsson C. Osteoblast-derived WNT16 represses osteoclastogenesis and prevents cortical bone fragility fractures. Nat Med. 2014;20(11):1279-88. Epub 2014/10/13. doi: 10.1038/nm.3654. PubMed PMID: 25306233; PMCID: PMC4392888.

48. Livak KJ, Schmittgen TD. Analysis of relative gene expression data using real-time quantitative PCR and the 2(-Delta Delta C(T)) Method. Methods. 2001;25(4):402-8. doi: 10.1006/meth.2001.1262. PubMed PMID: 11846609.

49. Li J, Sarosi I, Cattley RC, Pretorius J, Asuncion F, Grisanti M, Morony S, Adamu S, Geng Z, Qiu W, Kostenuik P, Lacey DL, Simonet WS, Bolon B, Qian X, Shalhoub V, Ominsky MS, Zhu Ke H, Li X, Richards WG. Dkk1-mediated inhibition of Wnt signaling in bone results in osteopenia. Bone. 2006;39(4):754-66. Epub 2006/05/30. doi: 10.1016/j.bone.2006.03.017. PubMed PMID: 16730481.

50. Zhou Q, Heinke J, Vargas A, Winnik S, Krauss T, Bode C, Patterson C, Moser M. ERK signaling is a central regulator for BMP-4 dependent capillary sprouting. Cardiovasc Res. 2007;76(3):390-9. Epub 2007/09/14. doi: 10.1016/j.cardiores.2007.08.003. PubMed PMID: 17850776.

51. Cervenka I, Wolf J, Masek J, Krejci P, Wilcox WR, Kozubik A, Schulte G, Gutkind JS, Bryja V. Mitogen-activated protein kinases promote WNT/beta-catenin signaling via phosphorylation of LRP6. 
855 Mol Cell Biol. 2011;31(1):179-89. Epub 2010/10/27. doi: 10.1128/MCB.00550-10. PubMed PMID:

20974802; PMCID: PMC3019858.

52. Gortazar AR, Martin-Millan M, Bravo B, Plotkin LI, Bellido T. Crosstalk between caveolin1/extracellular signal-regulated kinase (ERK) and beta-catenin survival pathways in osteocyte mechanotransduction. J Biol Chem. 2013;288(12):8168-75. Epub 2013/01/31. doi: 10.1074/jbc.M112.437921. PubMed PMID: 23362257; PMCID: PMC3605635.

53. Kim JM, Yang YS, Park KH, Oh H, Greenblatt MB, Shim JH. The ERK MAPK Pathway Is Essential for Skeletal Development and Homeostasis. Int J Mol Sci. 2019;20(8). Epub 2019/04/25. doi: 10.3390/ijms20081803. PubMed PMID: 31013682; PMCID: PMC6514701.

54. Krejci P, Aklian A, Kaucka M, Sevcikova E, Prochazkova J, Masek JK, Mikolka P, Pospisilova T, Spoustova T, Weis M, Paznekas WA, Wolf JH, Gutkind JS, Wilcox WR, Kozubik A, Jabs EW, Bryja V, Salazar L, Vesela I, Balek L. Receptor tyrosine kinases activate canonical WNT/beta-catenin signaling via MAP kinase/LRP6 pathway and direct beta-catenin phosphorylation. PLoS One. 2012;7(4):e35826. Epub 2012/05/05. doi: 10.1371/journal.pone.0035826. PubMed PMID: 22558232; PMCID: PMC3338780.

55. Gori F, Lerner U, Ohlsson C, Baron R. A new WNT on the bone: WNT16, cortical bone thickness, porosity and fractures. Bonekey Rep. 2015;4:669. Epub 2015/05/20. doi: 10.1038/bonekey.2015.36. PubMed PMID: 25987984; PMCID: PMC4432781.

56. Maeda K, Kobayashi Y, Udagawa N, Uehara S, Ishihara A, Mizoguchi T, Kikuchi Y, Takada I, Kato S, Kani S, Nishita M, Marumo K, Martin TJ, Minami Y, Takahashi N. Wnt5a-Ror2 signaling between osteoblast-lineage cells and osteoclast precursors enhances osteoclastogenesis. Nat Med. 2012;18(3):405-12. doi: 10.1038/nm.2653. PubMed PMID: 22344299.

57. Simsek Kiper PO, Saito H, Gori F, Unger S, Hesse E, Yamana K, Kiviranta R, Solban N, Liu J, Brommage R, Boduroglu K, Bonafe L, Campos-Xavier B, Dikoglu E, Eastell R, Gossiel F, Harshman K, Nishimura G, Girisha KM, Stevenson BJ, Takita H, Rivolta C, Superti-Furga A, Baron R. Cortical- 
880 Bone Fragility--Insights from sFRP4 Deficiency in Pyle's Disease. N Engl J Med. 2016;374(26):2553-

62. doi: 10.1056/NEJMoa1509342. PubMed PMID: 27355534; PMCID: PMC5070790.

58. Yoon JK, Lee JS. Cellular signaling and biological functions of R-spondins. Cell Signal. 2012;24(2):369-77. Epub 2011/10/11. doi: 10.1016/j.cellsig.2011.09.023. PubMed PMID: 21982879; PMCID: PMC3237830.

59. Azzolin L, Panciera T, Soligo S, Enzo E, Bicciato S, Dupont S, Bresolin S, Frasson C, Basso G, Guzzardo V, Fassina A, Cordenonsi M, Piccolo S. YAP/TAZ incorporation in the beta-catenin destruction complex orchestrates the Wnt response. Cell. 2014;158(1):157-70. Epub 2014/07/01. doi: 10.1016/j.cell.2014.06.013. PubMed PMID: 24976009.

60. de Lau W, Barker N, Low TY, Koo BK, Li VS, Teunissen H, Kujala P, Haegebarth A, Peters PJ, van de Wetering M, Stange DE, van Es JE, Guardavaccaro D, Schasfoort RB, Mohri Y, Nishimori K, Mohammed S, Heck AJ, Clevers H. Lgr5 homologues associate with Wnt receptors and mediate Rspondin signalling. Nature. 2011;476(7360):293-7. Epub 2011/07/06. doi: 10.1038/nature10337. PubMed PMID: 21727895.

61. Luo J, Zhou W, Zhou X, Li D, Weng J, Yi Z, Cho SG, Li C, Yi T, Wu X, Li XY, de Crombrugghe B, Hook M, Liu M. Regulation of bone formation and remodeling by G-protein-coupled receptor 48 . Development. 2009;136(16):2747-56. Epub 2009/07/17. doi: 10.1242/dev.033571. PubMed PMID: 19605502; PMCID: PMC2730404.

62. Xu P, Dang Y, Wang L, Liu X, Ren X, Gu J, Liu M, Dai X, Ye X. Lgr4 is crucial for skin carcinogenesis by regulating MEK/ERK and Wnt/beta-catenin signaling pathways. Cancer Lett. 2016;383(2):161-70. Epub 2016/10/25. doi: 10.1016/j.canlet.2016.09.005. PubMed PMID: 27693558.

63. Lin W, Xu L, Pan Q, Lin S, Feng L, Wang B, Chen S, Li Y, Wang H, Li Y, Wang Y, Lee WYW, Sun D, Li G. Lgr5-overexpressing mesenchymal stem cells augment fracture healing through regulation of Wnt/ERK signaling pathways and mitochondrial dynamics. FASEB J. 2019;33(7):8565-77. Epub 2019/04/18. doi: 10.1096/fj.201900082RR. PubMed PMID: 30991839. 
64. Vieira GC, Chockalingam S, Melegh Z, Greenhough A, Malik S, Szemes M, Park JH, Kaidi A, Zhou L, Catchpoole D, Morgan R, Bates DO, Gabb PD, Malik K. LGR5 regulates pro-survival MEK/ERK and proliferative Wnt/beta-catenin signalling in neuroblastoma. Oncotarget. 2015;6(37):40053-67. Epub 2015/10/31. doi: 10.18632/oncotarget.5548. PubMed PMID: 26517508; PMCID: PMC4741879.

65. Kamiya N, Shuxian L, Yamaguchi R, Phipps M, Aruwajoye O, Adapala NS, Yuan H, Kim HK, Feng JQ. Targeted disruption of BMP signaling through type IA receptor (BMPR1A) in osteocyte suppresses SOST and RANKL, leading to dramatic increase in bone mass, bone mineral density and mechanical strength. Bone. 2016;91:53-63. Epub 2016/07/13. doi: 10.1016/j.bone.2016.07.002. PubMed PMID: 27402532.

66. Kamiya N, Kobayashi T, Mochida Y, Yu PB, Yamauchi M, Kronenberg HM, Mishina Y. Wnt inhibitors Dkk1 and Sost are downstream targets of BMP signaling through the type IA receptor (BMPRIA) in osteoblasts. J Bone Miner Res. 2010;25(2):200-10. doi: 10.1359/jbmr.090806. PubMed PMID: 19874086; PMCID: 3153381.

67. Kamiya N, Ye L, Kobayashi T, Mochida Y, Yamauchi M, Kronenberg HM, Feng JQ, Mishina Y. BMP signaling negatively regulates bone mass through sclerostin by inhibiting the canonical Wnt pathway. Development. 2008;135(22):3801-11. Epub 2008/10/18. doi: 10.1242/dev.025825. PubMed PMID: 18927151; PMCID: PMC2694443.

68. Ko FC, Van Vliet M, Ellman R, Grasso D, Brooks DJ, Spatz JM, Conlon C, Aguirre JI, Wronski TJ, Bouxsein ML. Treatment With a Soluble Bone Morphogenetic Protein Type 1A Receptor (BMPR1A) Fusion Protein Increases Bone Mass and Bone Formation in Mice Subjected to Hindlimb Unloading. JBMR Plus. 2017;1(2):66-72. Epub 2018/10/05. doi: 10.1002/jbm4.10012. PubMed PMID: 30283882; PMCID: PMC6124165.

69. Shi C, Mandair GS, Zhang H, Vanrenterghem GG, Ridella R, Takahashi A, Zhang Y, Kohn DH, Morris MD, Mishina $\mathrm{Y}$, Sun $\mathrm{H}$. Bone morphogenetic protein signaling through ACVR1 and BMPR1A negatively regulates bone mass along with alterations in bone composition. J Struct Biol. 
930 2018;201(3):237-46. Epub 2017/11/28. doi: 10.1016/j.jsb.2017.11.010. PubMed PMID: 29175363;

931 PMCID: PMC5820174.

932 Acknowledgments

933 This work was supported by NIH-NIAMS R01AR064724 to R.B.

\section{Author contributions}

935 F.G. and R.B. conception of the work; K.N., K.Y., F.G. and R.B. design of the work; F.G. and R.B. 936 supervised the project; K.N., K.Y., H.S., R.K., A.C.P and D.R. acquisition and analysis of data; K.N., 937 K.Y., F.G. and R.B. interpretation of data; F.G. and R.B. wrote the paper, K.N. and C.N. contributed to 938 the writing and revision of the paper.

939 Competing interest statements

940 The Authors do not have competing interest. 
a

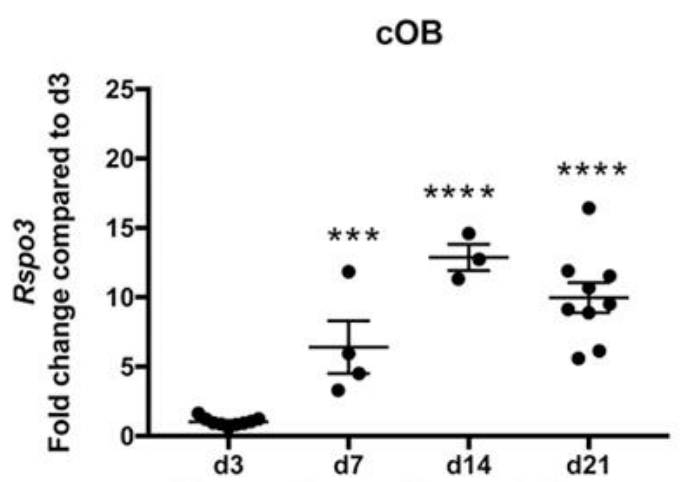

C

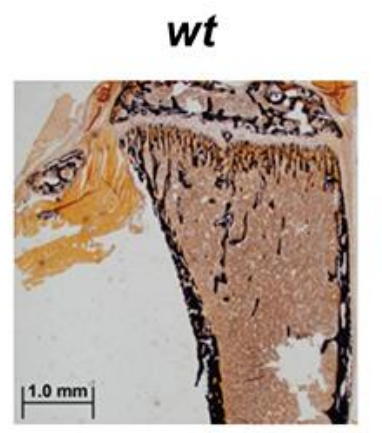

6wk b

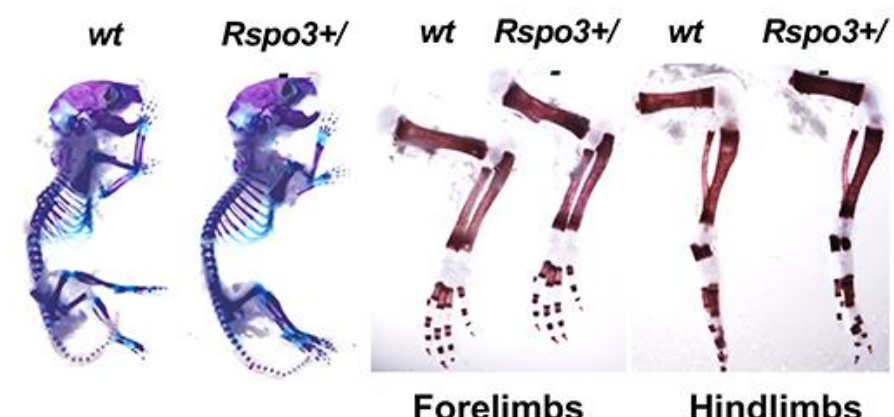

Forelimbs Hindlimbs

Figure S1. Skeletal phenotype of mice with Rspo3 haploinsufficiency. a) Rspo3 expression in calvarial OBs $(n=4-9)$. Data show all samples and the mean \pm SEM $(n=3-9){ }^{* *} p=0.0009$ and ${ }^{* \star \star * *}=p<0.0001$ compared to d3 by unpaired Student T test. b) Representative skeletal preparations of $w t$ and $R s p o 3^{+/}$ newborn (n=3-4). c) Representative images of Von Kossa staining of 6 and 18-wk old $w t$ and Rspo3 ${ }^{+/}$ males. 
a

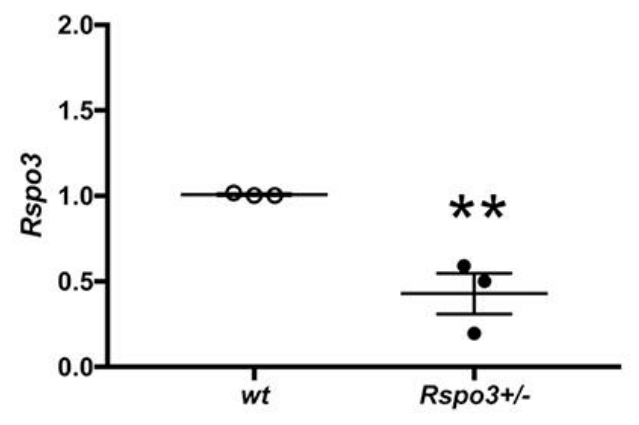

b

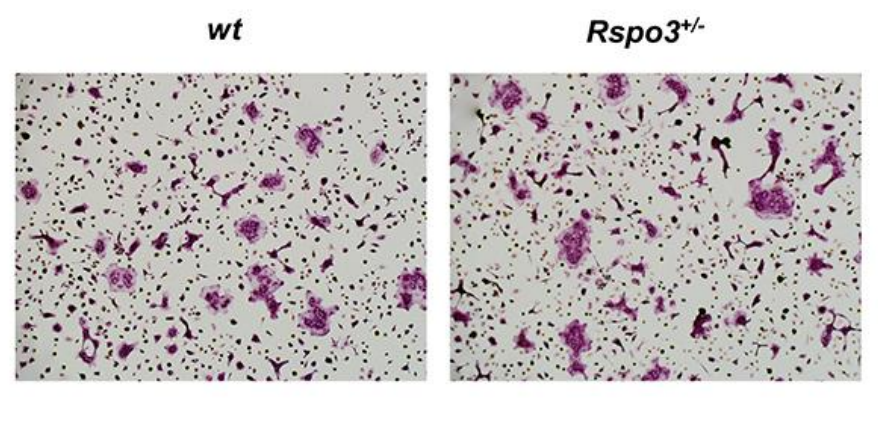

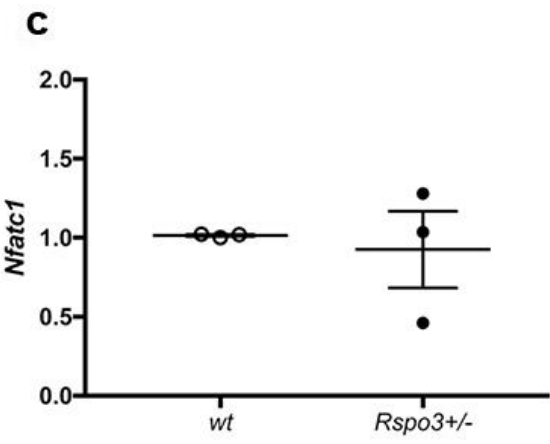

d

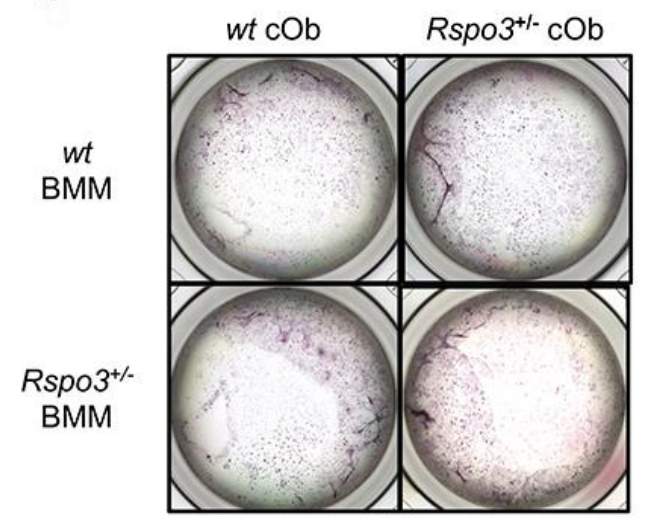

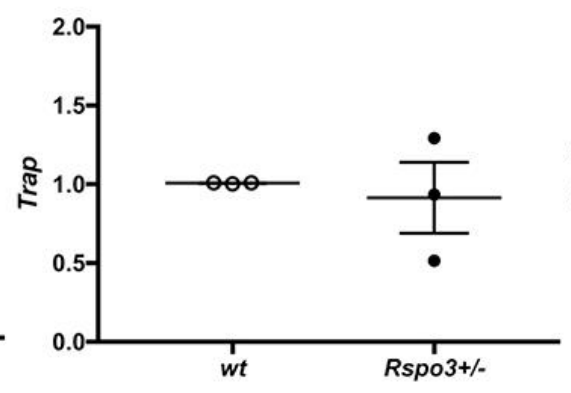

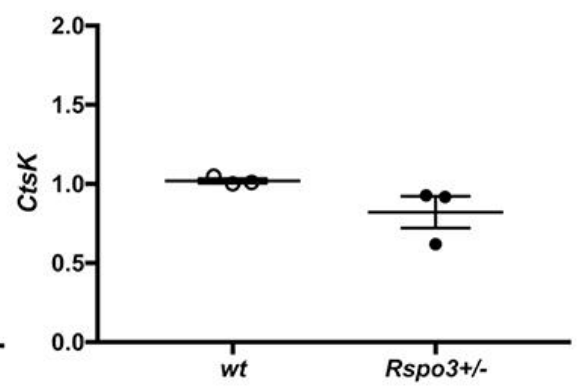

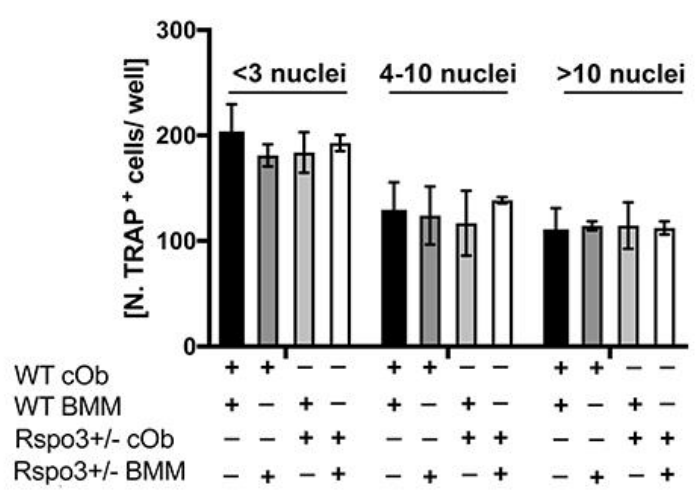

Figure S2. Rspo3 haploinsufficiency does not affect osteoclastogenesis. a) Rspo3 expression in BMMderived osteoclasts. b) Representative images of TRAP staining of $w t$ and $R s p o 3^{+/}$BMM-derived osteoclasts. c) Nfatc1, Trap and Ctsk expression in wt and Rspo3+/- BMM-derived osteoclasts. d)

955 Representative mix-matched experiment and quantification of TRAP+ BMM-derived osteoclast. Data 956 show all samples and the mean \pm SEM $(n=3){ }^{* *} p=0.0019$ by unpaired Student T test. 
Table S1. Histomorphometric analysis of $\mathrm{Rspo3}^{+-}$and wt males.

\begin{tabular}{|c|c|c|c|c|c|c|c|c|c|}
\hline \multirow[b]{2}{*}{ Parameters } & \multicolumn{2}{|l|}{$6 \mathrm{wk}$} & \multicolumn{2}{|l|}{$12 \mathrm{wk}$} & \multicolumn{2}{|l|}{$18 \mathrm{wk}$} & \multicolumn{3}{|c|}{ Two Way ANOVA } \\
\hline & $\begin{array}{l}\text { wt } \\
(\mathrm{n}=8)\end{array}$ & $\begin{array}{l}R_{\text {Rspo3 }}^{+/-} \\
(\mathrm{n}=7)\end{array}$ & $\begin{array}{l}w t \\
(\mathrm{n}=8)\end{array}$ & $\begin{array}{l}R s p o 3^{+/-} \\
(\mathrm{n}=9)\end{array}$ & $\begin{array}{l}w t \\
(\mathrm{n}=8)\end{array}$ & $\begin{array}{l}R_{\text {Rspo3 }}^{+/-} \\
(\mathrm{n}=6)\end{array}$ & Genotype & Age & Interaction \\
\hline BV/TV (\%) & $10.9 \pm 1.50$ & $10.4 \pm 1.41$ & $9.18 \pm 1.10$ & $14.3 \pm 1.23^{\star \star}$ & $8.18 \pm 0.56$ & $10.7 \pm 1.19$ & 0.0204 & NS & NS \\
\hline Tb.Th $(\mu \mathrm{m})$ & $30.9 \pm 1.94$ & $29.0 \pm 1.74$ & $34.7 \pm 2.01$ & $41.7 \pm 1.96^{\star}$ & $34.2 \pm 1.17$ & $39.4 \pm 2.02^{*}$ & 0.0248 & $<0.0001$ & 0.046 \\
\hline Tb.N (/mm) & $3.45 \pm 0.30$ & $3.51 \pm 0.30$ & $2.61 \pm 0.19$ & $3.41 \pm 0.22^{*}$ & $2.38 \pm 0.12$ & $2.68 \pm 0.22$ & 0.0476 & 0.0014 & NS \\
\hline Tb.Sp $(\mu \mathrm{m})$ & $273 \pm 27.1$ & $270 \pm 29.2$ & $365 \pm 32.1$ & $265 \pm 24.8^{* *}$ & $394 \pm 19.4$ & $348 \pm 30.9$ & 0,033 & 0.005 & NS \\
\hline $\operatorname{MAR}(\mu \mathrm{m} /$ day $)$ & $1.58 \pm 0.14$ & $2.01 \pm 0.13^{\star \star}$ & $1.23 \pm 0.07$ & $1.54 \pm 0.07^{\star}$ & $1.07 \pm 0.05$ & $1.21 \pm 0.06$ & 0.001 & $<0.0001$ & NS \\
\hline MS/BS (\%) & $23.3 \pm 1.17$ & $20.7 \pm 2.6$ & $45.3 \pm 3.60$ & $43.0 \pm 2.65$ & $26.1 \pm 2.58$ & $29.4 \pm 2.30$ & NS & $<0.0001$ & NS \\
\hline $\begin{array}{l}\text { BFR/BS } \\
\left(\mu \mathrm{m}^{3} / \mu \mathrm{m}^{2} / \text { year }\right)\end{array}$ & $136.3 \pm 16.5$ & $151 \pm 20.4$ & $201 \pm 13.9$ & $242 \pm 22.1$ & $103 \pm 14.0$ & $130 \pm 12.5^{\star *}$ & 0.029 & $<0.0001$ & NS \\
\hline $\begin{array}{l}\text { N.Ob/B.Pm } \\
(/ \mathrm{mm})\end{array}$ & $4.55 \pm 0.37$ & $5.17 \pm 0.21$ & $4.94 \pm 0.61$ & $7.39 \pm 0.97^{\star \star}$ & $4.05 \pm 0.48$ & $6.93 \pm 0.62^{* *}$ & 0.0006 & NS & NS \\
\hline Ob.S/B.Pm (\%) & $7.00 \pm 0.57$ & $8.80 \pm 0.38$ & $6.39 \pm 0.92$ & $10.4 \pm 1.58^{\star *}$ & $6.30 \pm 0.74$ & $11.2 \pm 0.93^{* *}$ & 0.0001 & NS & NS \\
\hline OS/BS (\%) & $2.87 \pm 0.38$ & $3.18 \pm 0.29$ & $4.62 \pm 1.10$ & $6.81 \pm 1.02^{*}$ & $4.16 \pm 0.62$ & $6.42 \pm 0.54$ & 0.0186 & 0.0033 & NS \\
\hline O.Th $(\mu \mathrm{m})$ & $2.91 \pm 0.23$ & $3.61 \pm 0.47$ & $3.09 \pm 0.22$ & $4.04 \pm 0.23^{*}$ & $3.65 \pm 0.40$ & $4.44 \pm 0.29$ & 0.0033 & NS & NS \\
\hline $\begin{array}{l}\text { N.Oc/B.Pm } \\
(/ \mathrm{mm})\end{array}$ & $0.95 \pm 0.08$ & $0.95 \pm 0.15$ & $2.29 \pm 0.11$ & $2.12 \pm 0.26$ & $1.33 \pm 0.07$ & $1.39 \pm 0.15$ & NS & $<0.0001$ & NS \\
\hline Oc.S/B.Pm (\%) & $2.95 \pm 0.40$ & $2.63 \pm 0.32$ & $5.87 \pm 0.24$ & $5.84 \pm 0.56$ & $3.83 \pm 0.25$ & $4.17 \pm 0.42$ & NS & $<0.0001$ & NS \\
\hline ES/BS (\%) & $4.27 \pm 0.52$ & $4.10 \pm 0.53$ & $1.61 \pm 0.33$ & $1.65 \pm 0.26$ & $4.38 \pm 0.27$ & $4.93 \pm 0.35$ & NS & $<0.0001$ & NS \\
\hline
\end{tabular}

Data are expressed as Mean \pm SEM. Two Way ANOVA followed by Fisher's LSD post-hoc test ${ }^{*}=p<0.05,{ }^{* *}=p<0.005$ compared to age-matched $w t$ males. 
962 Table S2. Histomorphometric analysis of the tibia midshaft in $12 \mathrm{wk}$-old wt and $\mathrm{Rspo3}^{+/-}$males.

\begin{tabular}{|c|c|c|c|c|c|c|c|c|c|}
\hline \multirow[b]{2}{*}{ Parameters } & \multicolumn{2}{|l|}{$6 \mathrm{wk}$} & \multicolumn{2}{|l|}{$12 \mathrm{wk}$} & \multicolumn{2}{|l|}{$18 \mathrm{wk}$} & \multicolumn{3}{|c|}{ Two Way ANOVA } \\
\hline & $\begin{array}{l}w t \\
(\mathrm{n}=6)\end{array}$ & $\begin{array}{l}\text { Rspo3 }^{+/-} \\
(\mathbf{n}=6)\end{array}$ & $\begin{array}{l}w t \\
(\mathrm{n}=5)\end{array}$ & $\begin{array}{l}R_{\left(n p o 3^{+/-}\right.} \\
(\mathbf{n}=5)\end{array}$ & $\begin{array}{l}w t \\
(\mathrm{n}=8)\end{array}$ & $\begin{array}{l}R^{R p o 3^{+/-}} \\
(\mathrm{n}=6)\end{array}$ & Genotype & Age & Interaction \\
\hline Ct.Ar[mm²] & $0.35 \pm 0.02$ & $0.34 \pm 0.01$ & $0.964 \pm 0.08$ & $0.85 \pm 0.085$ & $0.42 \pm 0.02$ & $0.4 \pm 0.017$ & NS & $<0.0001$ & NS \\
\hline $\operatorname{Ma} . \operatorname{Ar}\left[\mathrm{mm}^{2}\right]$ & $0.50 \pm 0.03$ & $0.49 \pm 0.0 .02$ & $1.181 \pm 0.08$ & $1.087 \pm 0.07$ & $0.74 \pm 0.04$ & $0.68 \pm 0.05$ & NS & $<0.0001$ & NS \\
\hline Tt.Ar[mm²] & $0.85 \pm 0.02$ & $0.86 \pm 0.02$ & $2.145 \pm 0.15$ & $2.112 \pm 0.142$ & $1.16 \pm 0.05$ & $1.07 \pm 0.06$ & NS & $<0.0001$ & NS \\
\hline Ct.BV/TV (\%) & $41.2 \pm 2.47$ & $40.9 \pm 0.77$ & $44.85 \pm 1.84$ & $48.4 \pm 1.52$ & $36.4 \pm 0.1$ & $36.8 \pm 1.41$ & NS & $<0.0001$ & NS \\
\hline Ct.Th (mm) & $157.4 \pm 15$ & $147 \pm 2.7$ & $203 \pm 12$ & $214 \pm 13$ & $180 \pm 12$ & $190 \pm 14$ & NS & 0.0007 & NS \\
\hline
\end{tabular}

963 Data are expressed as Mean \pm SEM. Two Way ANOVA followed by Fisher's LSD post-hoc test 
965 Table S3. Histomorphometric analysis of the tibia midshaft in $12 \mathrm{wk}$-old $w t$ and $R s p o 3^{+/-}$females.

\begin{tabular}{|c|c|c|c|c|c|c|c|c|c|}
\hline \multirow[b]{2}{*}{ Parameters } & \multicolumn{2}{|l|}{$6 \mathrm{wk}$} & \multicolumn{2}{|l|}{$12 \mathrm{wk}$} & \multicolumn{2}{|l|}{$18 \mathrm{wk}$} & \multicolumn{3}{|c|}{ Two Way ANOVA } \\
\hline & $\begin{array}{l}w t \\
(\mathrm{n}=6)\end{array}$ & $\begin{array}{l}\operatorname{Rspo3}^{+/-} \\
(\mathrm{n}=6)\end{array}$ & $\begin{array}{l}w t \\
(\mathrm{n}=4)\end{array}$ & $\begin{array}{l}R_{\text {Rspo3 }}^{+/-} \\
(\mathbf{n}=4)\end{array}$ & $\begin{array}{l}w t \\
(\mathrm{n}=8)\end{array}$ & $\begin{array}{l}R^{R p p o 3^{+/-}} \\
(\mathrm{n}=6)\end{array}$ & Genotype & Age & Interaction \\
\hline Ct.Ar[mm²] & $0.32 \pm 0.01$ & $0.32 \pm 0.007$ & $0.369 \pm 0.02$ & $0.404 \pm 0.02$ & $0.42 \pm 0.014$ & $0.42 \pm 0.015$ & NS & $<0.0001$ & NS \\
\hline $\operatorname{Ma} . \operatorname{Ar}\left[\mathrm{mm}^{2}\right]$ & $0.49 \pm 0.02$ & $0.55 \pm 0.02$ & $0.614 \pm 0.05$ & $0.684 \pm 0.05$ & $0.71 \pm 0.01$ & $0.6 \pm 0.04$ & NS & $<0.0001$ & 0.01 \\
\hline $\operatorname{Tt} . \operatorname{Ar}\left[\mathrm{mm}^{2}\right]$ & $0.81 \pm 0.02$ & $0.87 \pm 0.03$ & $0.983 \pm 0.05$ & $1.052 \pm 0.07$ & $1.12 \pm 0.02$ & $1.0 \pm 0.03$ & NS & $<0.0001$ & 0.02 \\
\hline Ct.BV/TV (\%) & $40 \pm 1.7$ & $36.9 \pm 0.9$ & $37.85 \pm 2.74$ & $38.53 \pm 0.6$ & $37.4 \pm 0.1$ & $42.5 \pm 2.2$ & NS & NS & 0.046 \\
\hline Ct.Th (mm) & $148.1 \pm 5.9$ & $147.8 \pm 5$ & $199 \pm 11$ & $212 \pm 10$ & $165 \pm 9$ & $178 \pm 8.4$ & NS & $<0.0001$ & NS \\
\hline
\end{tabular}

Data are expressed as Mean \pm SEM. Two Way ANOVA followed by Fisher's LSD post-hoc test 
968 Table S4. Histomorphometric analysis of $8 \mathrm{wk}$-old $R$ spo $3^{f l}$ and $R s p o 3^{O B}$ mice.

\begin{tabular}{|c|c|c|c|c|}
\hline \multirow[b]{2}{*}{ Parameters } & \multicolumn{2}{|l|}{ Male } & \multicolumn{2}{|l|}{ Female } \\
\hline & $\begin{array}{c}R_{s p o 3^{f l}} \\
(\mathrm{n}=10)\end{array}$ & $\begin{array}{c}\text { Rspo3 }^{O B} \\
(\mathrm{n}=10)\end{array}$ & $\begin{array}{c}\text { Rspo3 }^{f l} \\
(\mathrm{n}=7)\end{array}$ & $\begin{array}{l}\text { Rspo3 }^{O B} \\
(\mathrm{n}=9)\end{array}$ \\
\hline BV/TV (\%) & $6.18 \pm 0.37$ & $10.5 \pm 0.74^{\star \star \star \star}$ & $4.59 \pm 0.52$ & $6.61 \pm 0.52^{*}$ \\
\hline Tb.Th $(\mu \mathrm{m})$ & $21.0 .4 \pm 0.61$ & $25.3 \pm 1.16^{\star *}$ & $19.8 \pm 0.05$ & $21 \pm 0.6$ \\
\hline Tb.N (/mm) & $2.94 \pm 0.18$ & $4.15 \pm 0.18^{\star *}$ & $2.32 \pm 0.27$ & $3.11 \pm 0.17^{*}$ \\
\hline Tb.Sp $(\mu \mathrm{m})$ & $333.4 \pm 22$ & $220 \pm 10.5^{\star \star}$ & $451 \pm 56.5$ & $311 \pm 21^{*}$ \\
\hline MAR ( $\mu \mathrm{m} /$ day $)$ & $1.03 \pm 0.05$ & $1.7 \pm 0.07^{\star \star \star \star}$ & $1.32 \pm 0.11$ & $1.73 \pm 0.05^{\star \star}$ \\
\hline MS/BS (\%) & $31.2 \pm 1.16$ & $40.4 \pm 2.02^{\star \star}$ & $35.2 \pm 3.24$ & $39.0 \pm 1.38$ \\
\hline BFR/BS $\left(\mu \mathrm{m}^{3} / \mu \mathrm{m}^{2} /\right.$ year $)$ & $118.3 \pm 9.08$ & $251 \pm 17.3^{* *}$ & $167 \pm 16.4$ & $246 \pm 11.66^{* *}$ \\
\hline N.Ob/B.Pm (/mm) & $8.71 \pm 1.01$ & $15.8 \pm 2.16^{\star *}$ & $8.71 \pm 1.51$ & $13 \pm 0.1 .06^{*}$ \\
\hline Ob.S/B.Pm (\%) & $7.50 \pm 0.94$ & $14.2 \pm 2.44^{*}$ & $8.33 \pm 1.59$ & $12.7 \pm 1.05^{*}$ \\
\hline OS/BS (\%) & $4.42 \pm 0.73$ & $10.2 \pm 1.88^{\star *}$ & $8.33 \pm 1.29$ & $11.9 \pm 1.52$ \\
\hline O.Th $(\mu \mathrm{m})$ & $1.99 \pm 0.18$ & $2.72 \pm 0.20^{*}$ & $1.99 \pm 0.19$ & $2.29 \pm 0.10$ \\
\hline N.Oc/B.Pm (/mm) & $3.45 \pm 0.27$ & $2.8 \pm 0.27$ & $3.83 \pm 0.31$ & $3.22 \pm 0.20$ \\
\hline Oc.S/B.Pm (\%) & $6.54 \pm 0.41$ & $5.46 \pm 0.39$ & $7.83 \pm 0.46$ & $6.39 \pm 0.43^{*}$ \\
\hline ES/BS (\%) & $1.67 \pm 0.23$ & $1.53 \pm 0.41$ & $2.15 \pm 0.31$ & $1.92 \pm 0.32$ \\
\hline
\end{tabular}

Data are expressed as Mean \pm SEM. ${ }^{*}=\mathrm{p}<0.05,{ }^{* *}=\mathrm{p}<0.01,{ }^{* * * *}=\mathrm{p}<0.0001$ by unpaired Student's T-Test compared to gender-matched $R s p o 3^{f l}$ mice. 
Table S5. Histomorphometric analysis of 6 wk-old Control, Rspo3 ${ }^{+/,}$TgDkk1 and Rspo3 ${ }^{+/-; D k k 1-}$ Tg females.

\begin{tabular}{|c|c|c|c|c|c|c|c|}
\hline \multirow[t]{2}{*}{ Parameter } & \multirow{2}{*}{$\begin{array}{l}\text { Control } \\
(n=5)\end{array}$} & \multirow{2}{*}{$\begin{array}{l}R_{\text {spo3 }}^{+/-} \\
(\mathrm{n}=5)\end{array}$} & \multirow{2}{*}{$\begin{array}{l}\text { Dkk1-Tg } \\
(\mathrm{n}=5)\end{array}$} & \multirow{2}{*}{$\begin{array}{l}R s p o 3^{+/-; D k k 1-T g} \\
(\mathrm{n}=6)\end{array}$} & \multicolumn{3}{|c|}{ Two Way ANOVA } \\
\hline & & & & & Rspo3 & Dkk1 & Interaction \\
\hline BV/TV (\%) & $5.02 \pm 0.57$ & $7.83 \pm 0.75^{\mathrm{ac}}$ & $2.67 \pm 0.44^{a b}$ & $4.64 \pm 0.5^{\mathrm{bc}}$ & 0.0008 & 0.0002 & NS \\
\hline Tb.Th $(\mu \mathrm{m})$ & $29.0 \pm 1.65$ & $32.2 \pm 2.07$ & $28.8 \pm 2.34$ & $32.6 \pm 2.47$ & NS & NS & NS \\
\hline Tb.N (/mm) & $1.71 \pm 0.11$ & $2.4 \pm 0.01^{\mathrm{ac}}$ & $0.9 \pm 0.1^{\mathrm{ab}}$ & $1.43 \pm 0.12^{\mathrm{bc}}$ & $<0.0001$ & $<0.0001$ & NS \\
\hline Tb.Sp $(\mu \mathrm{m})$ & $586.1 \pm 30.9$ & $390.4 \pm 17.9^{c}$ & $1202 \pm 154^{a b}$ & $701.7 \pm 61.1^{\mathrm{bc}}$ & $<0.0001$ & $<0.0001$ & 0.0082 \\
\hline MAR ( $\mu \mathrm{m} /$ day $)$ & $1.63 \pm 0.2$ & $2.12 \pm 0.27$ & $1.12 \pm 0.13^{b}$ & $1.97 \pm 0.18^{c}$ & 0.007 & NS & NS \\
\hline MS/BS (\%) & $35.19 \pm 2.06$ & $37.7 \pm 2.37$ & $30.8 \pm 4.8$ & $42.9 \pm 2.04^{c}$ & 0.0194 & NS & NS \\
\hline BFR/BS $\left(\mu \mathrm{m}^{3} / \mu \mathrm{m}^{2} /\right.$ year $)$ & $212.8 \pm 34$ & $296 \pm 45.8^{c}$ & $127.8 \pm 27.2^{b}$ & $307.4 \pm 38.3^{c}$ & 0.0064 & NS & NS \\
\hline Ob.S/B.Pm (\%) & $18.75 \pm 1.63$ & $25.5 \pm 1.1^{\mathrm{ac}}$ & $8.9 \pm 1.16^{\mathrm{ab}}$ & $20.0 \pm 2.35^{b c}$ & $<0.0001$ & 0.0004 & NS \\
\hline N.Ob/B.Pm (/mm) & $14.6 \pm 0.92$ & $19.3 \pm 0.41^{\mathrm{ac}}$ & $7.2 \pm 0.82^{\mathrm{ab}}$ & $15.2 \pm 1.65^{\mathrm{bc}}$ & $<0.0001$ & 0.0001 & NS \\
\hline OS/BS (\%) & $13.05 \pm 1.53$ & $16.9 \pm 1.84^{c}$ & $7.32 \pm 1.9^{b}$ & $13.6 \pm 2.6^{c}$ & 0.0261 & 0.0435 & NS \\
\hline O.Th $(\mu \mathrm{m})$ & $4.35 \pm 0.30$ & $4.80 \pm 0.32^{c}$ & $2.68 \pm 0.51^{a b}$ & $4 \pm 0.25^{c}$ & 0.025 & 0.0025 & NS \\
\hline N.Oc/B.Pm (/mm) & $4.22 \pm 0.37$ & $4.56 \pm 0.27^{c}$ & $6.31 \pm 0.46^{\mathrm{ab}}$ & $5.11 \pm 0.38^{c}$ & NS & 0.0064 & NS \\
\hline Oc.S/B.Pm (\%) & $12.58 \pm 0.6$ & $12.77 \pm 0.51^{\mathrm{c}}$ & $16.9 \pm 1.18^{\mathrm{ab}}$ & $14.1 \pm 1.31^{c}$ & NS & 0.0087 & NS \\
\hline ES/BS (\%) & $4.51 \pm 0.7$ & $4.46 \pm 0.47$ & $5.14 \pm 0.48$ & $5.8 \pm 0.74$ & NS & NS & NS \\
\hline
\end{tabular}

Data are expressed as Mean \pm SEM. Two-Way ANOVA followed by Fisher's LSD post-hoc test.

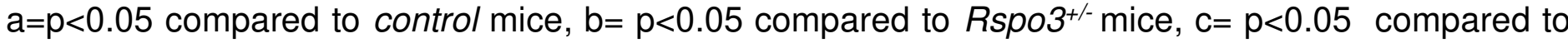
Dkk1-Tg mice. 


\section{Supplementary Files}

This is a list of supplementary files associated with this preprint. Click to download.

- GoriBaronSupplementarydocs.pdf 